\title{
Evolution of the codling moth pheromone via an ancient gene duplication
}

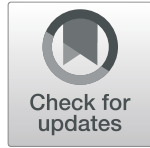

Jean-Marc Lassance ${ }^{1,2+}$ (D), Bao-Jian Ding ${ }^{1+}$ (I) and Christer Löfstedt ${ }^{1 *}$ (D)

\begin{abstract}
Background: Defining the origin of genetic novelty is central to our understanding of the evolution of novel traits. Diversification among fatty acid desaturase (FAD) genes has played a fundamental role in the introduction of structural variation in fatty acyl derivatives. Because of its central role in generating diversity in insect semiochemicals, the FAD gene family has become a model to study how gene family expansions can contribute to the evolution of lineage-specific innovations. Here we used the codling moth (Cydia pomonella) as a study system to decipher the proximate mechanism underlying the production of the $\Delta 8 \Delta 10$ signature structure of olethreutine moths. Biosynthesis of the codling moth sex pheromone, (E8,E10)-dodecadienol (codlemone), involves two consecutive desaturation steps, the first of which is unusual in that it generates an $E 9$ unsaturation. The second step is also atypical: it generates a conjugated diene system from the $E 9$ monoene $C_{12}$ intermediate via 1,4-desaturation.

Results: Here we describe the characterization of the FAD gene acting in codlemone biosynthesis. We identify 27 FAD genes corresponding to the various functional classes identified in insects and Lepidoptera. These genes are distributed across the C. pomonella genome in tandem arrays or isolated genes, indicating that the FAD repertoire consists of both ancient and recent duplications and expansions. Using transcriptomics, we show large divergence in expression domains: some genes appear ubiquitously expressed across tissue and developmental stages; others appear more restricted in their expression pattern. Functional assays using heterologous expression systems reveal that one gene, CPo_CPRQ, which is prominently and exclusively expressed in the female pheromone gland, encodes an FAD that possesses both E9 and $\triangle 8 \Delta 10$ desaturation activities. Phylogenetically, Cpo_CPRQ clusters within the Lepidoptera-specific $\triangle 10 / \Delta 11$ clade of FADs, a classic reservoir of unusual desaturase activities in moths.

Conclusions: Our integrative approach shows that the evolution of the signature pheromone structure of olethreutine moths relied on a gene belonging to an ancient gene expansion. Members of other expanded FAD subfamilies do not appear to play a role in chemical communication. This advises for caution when postulating the consequences of lineage-specific expansions based on genomics alone.
\end{abstract}

Keywords: Fatty acyl desaturase, Gene family evolution, Bifunctional, Conjugated double bond, Tortricidae

\footnotetext{
* Correspondence: christer.lofstedt@biol.lu.se

${ }^{\dagger}$ Jean-Marc Lassance and Bao-Jian Ding contributed equally to this work. 'Department of Biology, Lund University, Sölvegatan 37, SE-223 62 Lund, Sweden

Full list of author information is available at the end of the article
}

(c) The Author(s). 2021 Open Access This article is licensed under a Creative Commons Attribution 4.0 International License, which permits use, sharing, adaptation, distribution and reproduction in any medium or format, as long as you give appropriate credit to the original author(s) and the source, provide a link to the Creative Commons licence, and indicate if changes were made. The images or other third party material in this article are included in the article's Creative Commons licence, unless indicated otherwise in a credit line to the material. If material is not included in the article's Creative Commons licence and your intended use is not permitted by statutory regulation or exceeds the permitted use, you will need to obtain permission directly from the copyright holder. To view a copy of this licence, visit http://creativecommons.org/licenses/by/4.0/. The Creative Commons Public Domain Dedication waiver (http://creativecommons.org/publicdomain/zero/1.0/) applies to the data made available in this article, unless otherwise stated in a credit line to the data. 


\section{Background}

Establishing the origin of genetic novelty and innovation is central to our understanding of the evolution of novel traits. While genes can evolve de novo in the genome, the most common mechanism involves duplications of existing genes and the subsequent evolution of novel properties harbored by the encoded gene products. Expansions provide opportunities for specialization and evolution of novel biological functions within a lineage, including the breadth of expression via modifications of promoter architecture [1]. The size of gene families is influenced by both stochastic processes and selection, and particularly large differences in genetic makeup can be indicative of lineage-specific adaptation and potentially associate with traits contributing to phenotypical differentiation between groups [2, 3]. However, the precise functional consequences of such amplifications remain frequently unclear, even if expansions show readily discernible patterns. Therefore, deciphering the underlying genetic and molecular architecture of new phenotypic characters is necessary for a complete understanding of the role played by the accumulation of genetic variation through gene duplication.

For organisms relying on chemical communication, evolution of the ability to produce and detect a new type of molecule could allow for the expansion of the breadth of available communication channels and provide a medium with no or limited interference from other broadcasters. Since the identification of bombykol by Butenandt and co-workers in 1959 [4], a countless number of studies have contributed to revealing the diversity of fatty acid derivatives that play a pivotal role in the chemical communication of insects. As a consequence of homologies with well-studied metabolic pathways, our understanding of the molecular basis of pheromone biosynthesis from fatty acid intermediates has greatly advanced over the past two decades, highlighting the role of several multigene families [5]. Insect semiochemicals are synthesized in specialized cells in which fatty acyl intermediates are converted in a stepwise fashion by a combination of desaturation, chain-shortening, and chain-elongation reactions followed by modifications of the carbonyl group, to cite a few possible steps $([5,6]$ and references therein). Desaturation appears particularly important and contributes to producing the great diversity of structures observed in insect pheromones. This derives from the properties of the enzymes that are central to many uncanonical fatty acid synthesis pathways seen in insects. These enzymes can exhibit diverse substrate preference, introduce desaturation in either or both cis $(Z)$ and trans $(E)$ geometry, and give rise to variation in chainlength double-bond position, number, and configuration.

In insects, the group of proteins responsible for catalyzing desaturation reactions are fatty acyl-CoA desaturases
(FADs). These membrane-bound acyl-lipid desaturases are biochemically and structurally homologous to the desaturases ubiquitously found in animals, yeast, fungi, and many bacteria where they play important basic biological functions in lipid metabolism and cell signaling and contribute to membrane fluidity in response to temperature fluctuation [7]. In the past decades, the integration of molecular and phylogenetic approaches has greatly advanced our understanding of the function of FAD genes in the biosynthesis of mono- and polyunsaturated fatty acids in a range of organisms. Moreover, an ever-increasing number of acyl-CoA desaturase genes have been functionally characterized, demonstrating mechanistically their crucial role in the biosynthesis of pheromone and semiochemicals in Drosophila fruitflies, bees, wasps, beetles, and lepidopteran species. Variation in the number and expression of acyl-CoA desaturase genes have been shown to affect the diversity of pheromone signals between closely related species [8-12]. The family is characterized by multiple episodes of expansion and contraction that occurred during the evolution of insects $[13,14]$. Consequently, the FAD gene family has become a model to study how structural and regulatory changes act in concert to produce new phenotypes.

Among the taxa available to study the molecular basis of pheromone production in an evolutionary framework, leafroller moths (Lepidoptera: Tortricidae) provide a model system of choice [15]. Leafrollers represent one of the largest families in the Lepidoptera with over 10,000 described species [16]. Their larvae feed as leaf rollers, leaf webbers, leaf miners, or borers in plant stems, roots, fruits, or seeds. Many tortricid species are important pests and, due to their economic impact on human society, became the target of many pheromone identification studies. In 1982, Roelofs and Brown published a comprehensive review on pheromones and evolutionary relationships among Tortricidae [17]. These authors related the patterns in pheromone diversity in a biosynthetic perspective to different postulated phylogenies of the Tortricidae, and specifically the two major groups within Tortricidae, Tortricinae and Olethreutinae. Based on the pheromone identifications available at the time, it was suggested that species in the Tortricinae use mostly 14carbon pheromone components (acetates, alcohols, and aldehydes) whereas species in the Olethreutinae subfamily use mostly 12 -carbon compounds. Building on recent advances towards a robust molecular phylogeny of Tortricidae $[18,19]$ and incorporating the information for the pheromones identified in 179 species and sex attractants reported for an additional 357 species, we show that the proposed dichotomy is well-supported by the data currently available (Fig. 1). Furthermore, a majority of species in Tortricinae use pheromone components with double bonds in uneven positions, i.e., $\Delta 9$ isomers 


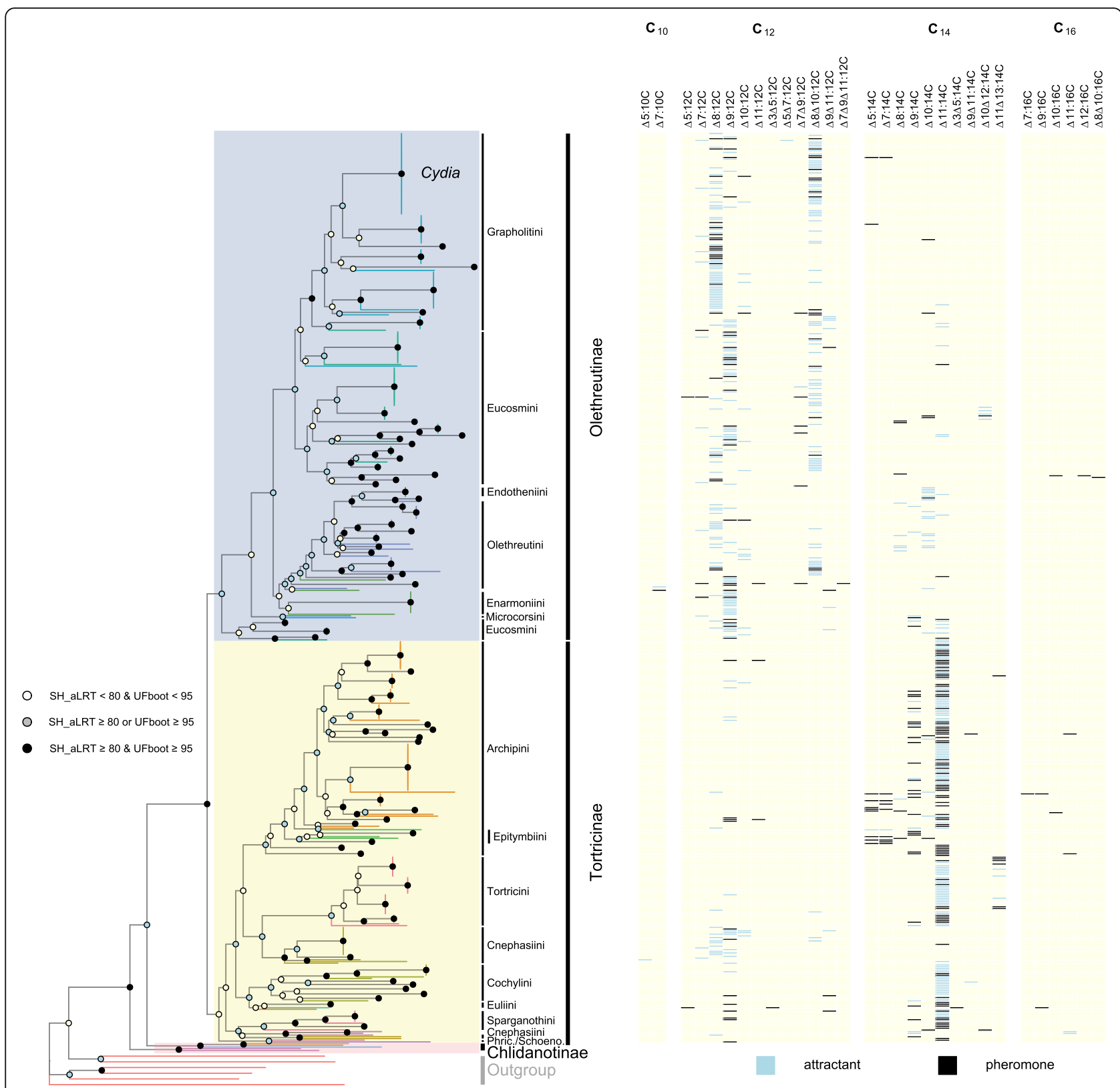

Fig. 1 Phylogeny of Tortricidae and their associated female sex pheromone components. (left) The maximum likelihood tree was obtained for predicted nucleotide sequences of Tortricidae species (7591 aligned positions). The species represented comprise all tortricids for which pheromones or attractants have been reported plus some outgroups. Typically, one representative species was chosen per genus and contributed molecular evidence for all species in the genus. Outgroup species are represented by red branches whereas tortricid species from the same tribe are represented by branches of the same color. Branch support values were calculated from 1000 replicates using the Shimodaira-Hasegawa-like approximate ratio test (SH_aLRT) and ultrafast bootstrapping (UFboot). Support values for branches are indicated by colored circles, with color assigned based on thresholds of branch selection for SH-aLRT (80\%) and UFBoot (95\%) supports, respectively. The major subfamilies and represented tribe names are indicated (Phric: Phricanthini; Schoeno: Schoenotenini). (right) Heatmap representing the presence/absence of unsaturated fatty acid structure in bioactive molecules. Attractants correspond to compounds found to be attractive in either field or laboratory experiments; pheromone components correspond to sex attractants produced naturally by the organism and with a demonstrated biological activity on conspecific males. Double-bond positions are annotated in $\Delta$-nomenclature without referring to the geometry. Molecular and trait data retrieved from GenBank and the Pherobase, respectively

or $\Delta 11$ isomers. By contrast, the Olethreutinae pheromones typically contain components with double bonds in even positions $(\Delta 8, \Delta 10)$, with doubly unsaturated $\Delta 8 \Delta 10$ : $12 \mathrm{C}$ fatty acyl chains being one of the signature structures of the subfamily. Roelofs and Brown [17] suggested that the use of a Lepidoptera-specific $\Delta 11$-desaturase acting on myristic acid $\left(\mathrm{C}_{14}\right)$ could account biosynthetically for most of the pheromone compounds found in Tortricinae. This 
hypothesis was later confirmed with the functional characterization of FADs expressed in the female pheromone gland of several Tortricinae representatives. These include a desaturase that makes only the E11-isomer in the light brown apple moth Epiphyas postvittana (E11-14, E11-16, and E9E11-14) [20], as well as desaturases from the redbanded leafroller moth Agryrotaenia velutinana [21] and the obliquebanded leafroller moth Choristoneura rosaceana [22] which both produce a mixture of Z/E11-14:Acids. In the case of Olethreutinae, $\Delta 11$ desaturation followed by chain-shortening could account for the $\Delta 9: 12 \mathrm{C}$ compounds found in several tribes of Olethreutinae. On the other hand, the biochemical pathways leading to the pheromone components with double bonds in even positions, the $\Delta 8$ and $\Delta 10$ as well as the doubly unsaturated $\Delta 8 \Delta 10: 12 \mathrm{C}$ compounds in the Olethreutinae, were not obvious.

The codling moth Cydia pomonella (Linnaeus) (Tortricidae: Olethreutinae: Grapholitini) is one of the most devastating pests in apple and pear orchards worldwide [23]. With the goal of disrupting its reproduction, it has received substantial attention and been at the center of numerous studies focused on characterizing its communication system via sex pheromones. Its pheromone, (E8,E10)-dodecadien-1-ol, also known under the common name codlemone, was first identified using gas chromatography in combination with electroantennogram (EAG) recordings [24]. This identification was later confirmed by fine chemical analysis $[25,26]$. The codling moth thus provides a relevant system to unravel the molecular pathway associated with the production of the $\Delta 8 \Delta 10: 12 \mathrm{C}$ typical of olethreutines. Previous studies support the hypothesis that the biosynthesis involves the desaturation of a $\Delta 9$ monoene intermediate. First, Arn et al. [27] reported the presence of the unusual (E)-9-dodecenol (E9-12:OH) at about $10 \%$ of the doubly unsaturated alcohol in pheromone gland extracts and effluvia from C. pomonella females. Although this monoene does not carry any behavioral activity, its occurrence suggested that E9-12:Acyl could be an intermediate of codlemone biosynthesis in a process analogous to the biosynthesis of 10,12dienic systems via $\Delta 11$ monoene intermediates observed in Bombyx mori, Manduca sexta, and Spodoptera littoralis [28-30]. The selective incorporation of deuterium-labeled E9-12 fatty acid precursors into codlemone and its direct precursor, E8,E10-dodecadienoate (E8E10-12:Acyl), supported the presence of an unusual $\Delta 9$ desaturase in $C$. pomonella and the biosynthesis of a conjugated diene system via 1,4-desaturation and the characteristic elimination of two hydrogen atoms at the allylic position of the double bond in the monoene intermediate precursor [31] (Fig. 2).

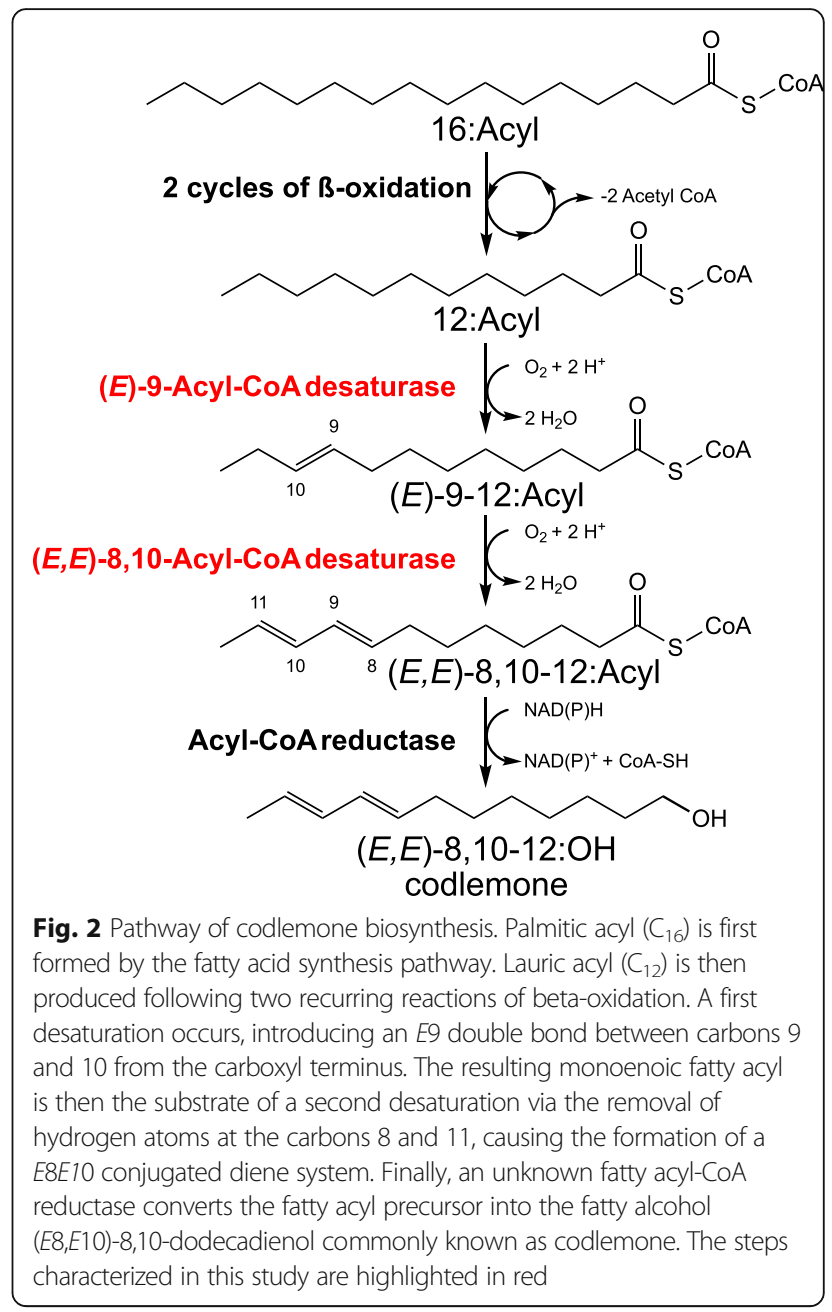

Similar conclusions were reached from a replicate study using C. splendana and C. nigricana females [32]. To date, the $\mathrm{FAD}(\mathrm{s})$ central to the biosynthesis of codlemone and related fatty acyl derivates with a $\Delta 8 \Delta 10$ system has not been characterized.

The availability of a high-quality draft genome for $C$. pomonella provides an opportunity to comprehensively annotate and analyze relevant genes [33]. Here we annotated a total of 27 FAD genes and performed a phylogenetic analysis, revealing expansions of different ages in the $\Delta 9$ (KPSE) clade and in the $\Delta 10 / \Delta 11$ (XXXQ/ E) clade. Using a transcriptomic approach, we determine the breadth of expression of all FAD genes and identified genes with upregulated expression in the pheromone gland of female C. pomonella, where the biosynthesis of codlemone takes place. We tested the function of these desaturases in heterologous expression systems and identified one FAD gene conferring on the cells the dual desaturase functions playing a key role in the biosynthesis of $(E 8, E 10)$-dodecadienol in C. pomonella and a signature structure of many Olethreutinae moth pheromones. 


\section{Results}

\section{Expansion of FADs in the genome of $C$. pomonella}

We identified candidates potentially involved in fatty acid synthesis by searching in the genome of $C$. pomonella for genes encoding fatty acid desaturases, which are characterized by a fatty acid desaturase type 1 domain (PFAM domain PF00487). First, we improved the genome annotation by incorporating data from the pheromone gland transcriptome, a tissue which was not part of the panel of tissues used to generate the available annotation of $C$. pomonella. Searching our improved annotation, we identified 27 genes harboring the signature domain of FADs. While the vast majority of genes identified in our exhaustive search contain open-reading frames of 300 amino acids or longer, a small number of genes (i.e., 2-3) may represent pseudogenes or assembly errors. We adopted the nomenclature proposed by Knipple et al. [34] in which genes are named based on the composition of 4 amino acid residues at a signature motif. Next, we looked at their genomic organization. We found that FAD genes are distributed across 12 of the 27 autosomes, with no FAD genes on either Z or W sex chromosome (chr1 and chr29, respectively) (Fig. 3). Two genes, Cpo_QPVE and Cpo_ $\operatorname{MATD}(2)$, were found on unplaced scaffolds. As is typical for members of a multigene family, we identify several clusters corresponding to tandemly duplicated genes. Moreover, several genes are present as the single member of the family on a given autosome.

\section{Phylogenetic analyses place expansions in the $\Delta 9$ (KPSE) and $\Delta 10 / \Delta 11(X X X Q / E)$ clades}

In order to determine which of the genes identified above could be important for codlemone biosynthesis, we assessed the functional classes represented by these genes using phylogenetic analyses. To that end, we aligned the predicted protein sequences of the $C$. pomonella genes with a panel of FAD sequences from Lepidoptera species including genes for which function has been previously characterized using in vitro heterologous expression. We found representatives of the eight insect acyl-CoA desaturase subfamilies sensu Helmkampf et al. [14] (Fig. 4; Additional file 1: Figure S1).

All subfamilies form highly supported groups, with the exception of the relationship between Desat A1 and A2, which appear weakly or strongly supported, depending on the set of genes used in our analyses. With a characteristic domain architecture (PF08557 in front of PF00487), Cpo_TYSY encodes a putative Sphingolipid Delta-4 desaturase and is homologous to interfertile crescent in D. melanogaster (Ifc). Two tandemly duplicated genes, Cpo_RIDY and Cpo_DRKD, contain a Cytochrome b5-like heme binding domain (PF00173) in front of the fatty acid desaturase domain and group with putative Front-End desaturases homologous to Cytochrome b5-related in D. melanogaster (Cyt-b5-r). These three genes bear little similarity with the other 24 FAD genes which encode First Desaturases of the subfamilies Desat A1 through E.

Desat $\mathrm{C}, \mathrm{D}$, and $\mathrm{E}$ are present as single-copy genes in C. pomonella (Cpo_QPVE, Cpo_KSTE, and Cpo_KYPH, respectively). Cpo_QPVE groups with the $\Delta 14$ desaturase identified in male and female corn borer pheromone biosynthesis (Lepidoptera: Crambidae) [9, 35].

Desat $\mathrm{B}$, which is particularly expanded in Hymenopterans and in Bombyx mori [14], has only two representatives in $C$. pomonella. These genes, CPo_VKVI and Cpo_TPVE, are homologous to the E6 desaturase identified in Antheraea pernyi (Lepidoptera: Saturnidae) [36] and the Z5 desaturase identified in Ctenopseustis obliquana (Lepidoptera: Tortricidae) [37], respectively.

Desat A2 subfamily is characterized by a single-copy gene, Cpo_GATD, which seems to be typical of Lepidoptera. The homolog identified in Choristoneura parallela (Lepidoptera: Tortricidae) is associated with the formation of $\Delta 9$ desaturation in saturated acyl moieties of a range of length $\left(\mathrm{C}_{14}-\mathrm{C}_{26}\right)$ [38].

Finally, Desat A1 forms the largest group and experienced a particularly dynamic evolutionary history. With 17 genes, $C$. pomonella harbors twice as many genes as Bombyx mori (7 in the most recent version of the genome SilkDB 3.0 [39]). While $\Delta 9 \mathrm{C} 16<\mathrm{C} 18$ (NPVE) is represented by a single-copy gene, we found two significant expansions in the group corresponding to $\Delta 9$ C16>C18 (KPSE) and $\Delta 11, \Delta 10$, and bifunctional (XXXQ/E) FADs. The tandemly arrayed cluster found in chr4 corresponds to an extension within the A1 subfamily encoding $\Delta 9 \mathrm{C} 16>\mathrm{C} 18$ FADs. Nine genes are found in the Lepidoptera-specific A1 subfamily encoding $\Delta 11$, $\Delta 10$, and bifunctional FADs. These genes are scattered across 6 private chromosomes, none of which containing members of the other functional classes.

Based on their placement in the FAD gene tree, these genes can be sub-divided into four groups (Fig. 4; Additional file 1: Figure S1). Group1 contains Cpo_ SPTQ(1), Cpo_SPTQ(2), Cpo_SATK, and Cpo_TSTQ, which are homologous to the $\Delta 10$ desaturase identified in the New Zealand tortricid Planotortrix octo (Lepidoptera: Tortricidae) [40]. Group2 is formed with Cpo_RATE, Cpo_ MATE, and CPo_TPSQ, which are homologous to the FAD with $\Delta 6$ activity isolated from Ctenopseustis herana (Lepidoptera: Tortricidae) [12]. Group3 is represented by Cpo_RPVE, which groups with desat2 from Ctenopseustis obliquana and allied species (Lepidoptera: Tortricidae) [12] and Lca_KPVQ from Lampronia capitella (Lepidoptera: Prodoxidae) [41]. Finally, Cpo_CPRQ falls near Dpu_LPAE from Dendrolimus punctatus (Lepidoptera: Lasiocampidae) [42]. Based on our phylogenetic reconstructions, several genes are plausible candidates in the biosynthesis of codlemone. First, genes from the $\Delta 9 \mathrm{C} 16>\mathrm{C} 18$ (KPSE) subfamily 


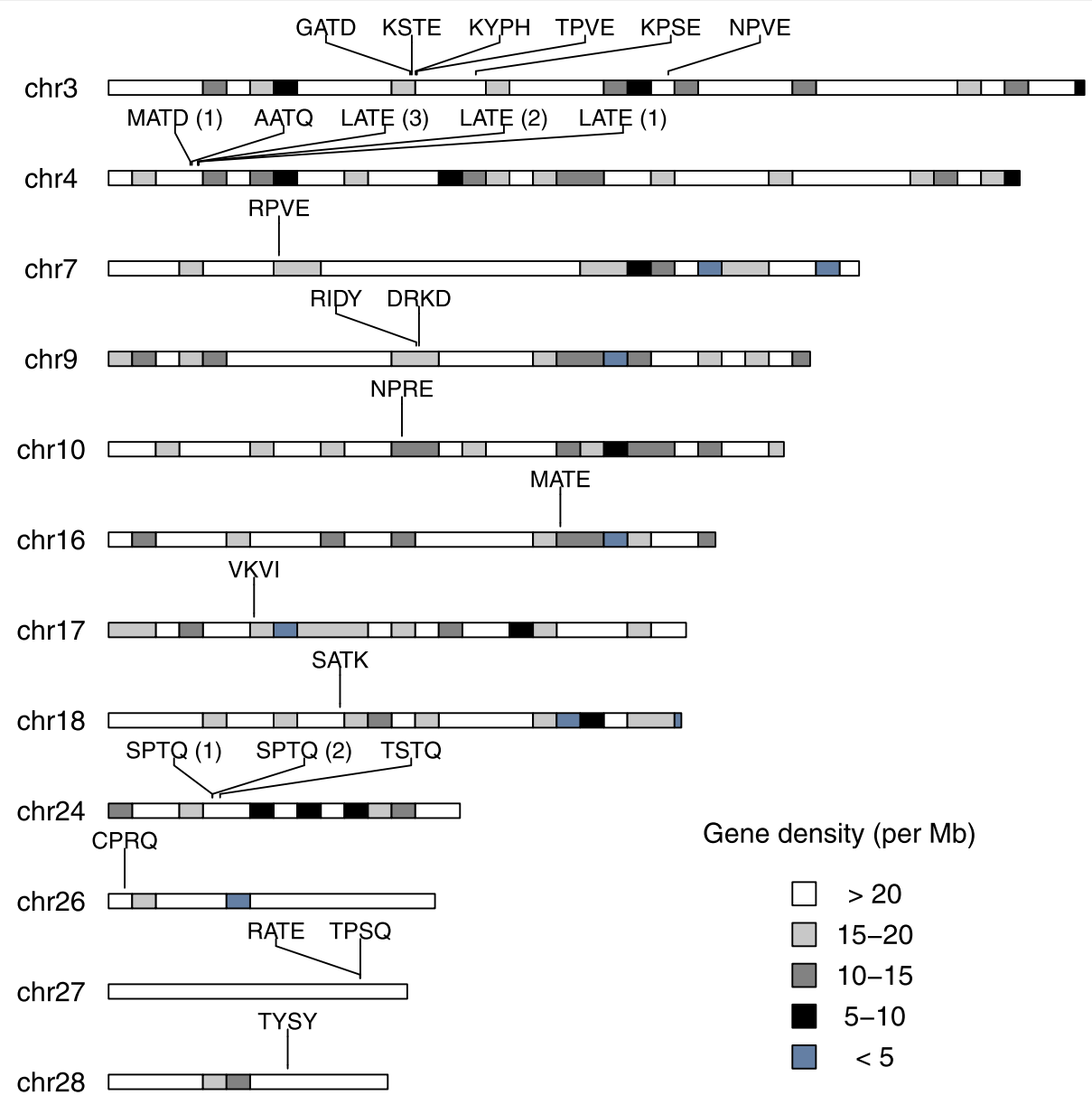

Fig. 3 Genomic organization of fatty acyl desaturase genes in Cydia pomonella. The positions of the 27 predicted FAD genes were mapped to the genome. Twenty-five genes could be placed on 12 autosomes; 2 genes, Cpo_MATD(2) and Cpo_QPVE, are located on unplaced scaffolds (not drawn). The distribution analysis showed that there are 5 gene clusters which contain 2 or more FAD genes. Names refer to chromosome names in the genome assembly. Chromosomes are drawn to scale and the bands represent gene density, with darker bands depicting gene-poor regions

have been implicated in pheromone biosynthesis and carry activities similar to those expected in C. pomonella. Specifically, the Dpu_KPSE from Dendrolimus punctatus (Lepidoptera: Lasiocampidae) produces a range of $\Delta 9$ monounsaturated products including Z9- and E9-12:Acyl [42]. This exemplifies that enzymes in this subfamily can introduce cis and trans double bonds in lauric acid $\left(\mathrm{C}_{12}\right)$. Furthermore, when supplemented with Z7- and E7-14:Acyl, Dpu_KPSE can introduce a second desaturation to produce $\Delta 7 \Delta 9-14$ :Acyl, illustrating the formation of conjugated double bonds by this type of FAD. The expansion of the KPSE clade we report in C. pomonella is an interesting coincidence. Second, the abundance of representatives in the $\Delta 11, \Delta 10$, and bifunctional (XXXQ/E) subfamily supports the possibility that one or several could be involved in codlemone biosynthesis. This group contains many genes involved in the biosynthesis of conjugated double bonds, e.g., Bmo_KATQ in Bombyx mori (Lepidoptera: Bombycidae) [43], Mse_APTQ in Manduca sexta (Lepidoptera:
Sphingidae) [44], Lca_KPVQ in Lampronia capitella (Lepidoptera: Prodoxidae) [41], and Dpu_LPAE in Dendrolimus punctatus [42]. Cpo_RPVE groups with Lca_KPVQ, which encodes an enzyme involved in the desaturation of 16:Acyl and Z9-14:Acyl to produce the conjugated Z9Z11-14:Acyl pheromone precursor of L. capitella [41]. Another interesting candidate is Cpo_CPRQ, which clusters near Dpu LPAE, an enzyme capable of catalyzing the production of E9Z11-16:Acyl and E9E11-16:Acyl [42].

\section{Patterns of gene expression identify Cpo_CPRQ and Cpo_SPTQ(1) as candidates}

To identify candidates for codlemone production, we compared the expression levels of the twenty-seven genes found in the genome using published RNA sequencing (RNA-Seq) data from various tissues and life stages augmented with two new pheromone gland data sets (this study). Since codlemone is found in the pheromone gland of females, which is located at the tip of the 


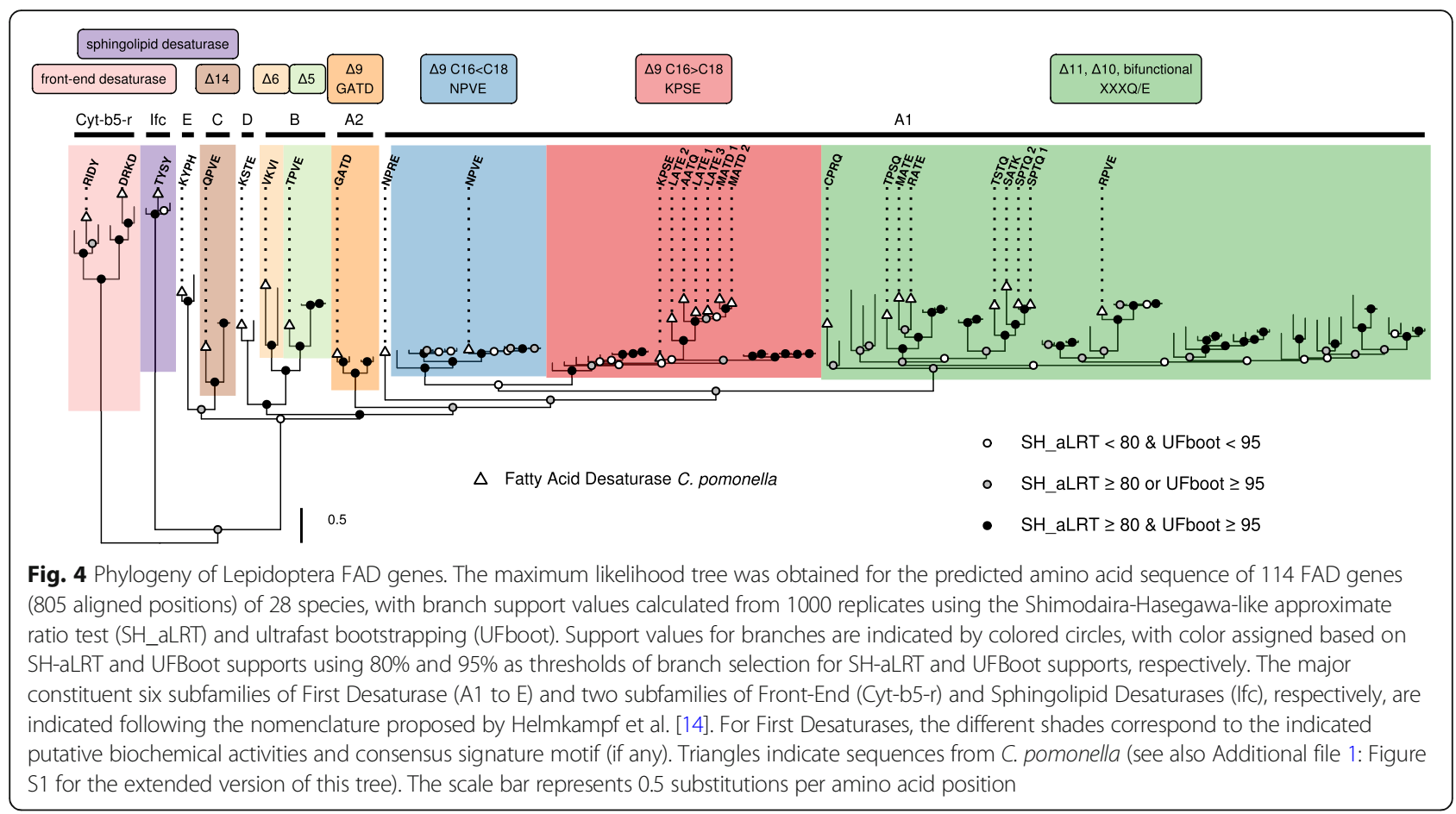

abdomen, we hypothesized that its desaturase(s) would be enriched or even exclusively expressed in this sex and in the population of cells forming this tissue.

We found strong qualitative differences in the transcription profile of the 27 examined FAD genes (Fig. 5). The genes divide into three clusters. The first two correspond to genes that appear ubiquitously expressed. These include the two putative Front-End desaturases Cpo_DRKD and Cpo_RIDY (Cyt-b5-r), the Sphingolipid $\Delta 4$ desaturase CPo_TYSY (Ifc), and five First desaturases, namely Cpo_NPVE (A1; $\Delta 9 \mathrm{C} 16<\mathrm{C} 18)$, Cpo_KPSE (A1; $\Delta 9$ C16>C18), Cpo_RPVE (A1; $\Delta 11 / \Delta 10)$, Cpo_KSTE (D), and Cpo_KYPH (E). With the exception of Cpo_RPVE, these genes exhibit a high evolutionary stability characterized by a single-copy gene with rare cases of gains and losses across insects. Their broad expression profiles suggest that these genes fulfill a fundamental metabolic function, making them unlikely candidates for pheromone biosynthesis. By contrast, the other First Desaturase genes found in the third cluster are characterized by a sparse expression profile and greater tissue and/or life-stage specificity: head: Cpo_TPSQ (A1; $\Delta 11 / \Delta 10$ ); ovary/female abdomen: Cpo_TPVE (B; $\Delta 5)$; pheromone gland: $\mathrm{Cpo}_{-}$ CPRQ (A1; $\Delta 11 / \Delta 10)$, CPo_SPTQ(1) (A1; $\Delta 11 / \Delta 10)$; and eggs: Cpo_NPRE (A1), Cpo_VKVI (B; $\Delta 6)$. These expression patterns are suggestive of more specialized functions. Specifically, their expression profiles and levels indicated that Cpo_CPRQ and Cpo_SPTQ(1) (average FPKM in pheromone gland, 6082.0 and 1451.5 , respectively) represent primary candidates for functional testing.

\section{Functional characterization demonstrates the E9 FAD activity of Cpo_CPRQ and Cpo_SPTQ(1)}

Previous studies have shown that the baker's yeast Saccharomyces cerevisiae is a convenient system for studying in vivo the function of FAD genes and it has become the eukaryotic host of choice for the heterologous expression of desaturases from diverse sources including moths. Conveniently, yeast cells readily incorporate exogenous fatty acid methyl esters and convert them to the appropriate coenzyme A thioester substrates required by FADs.

First, we cloned Cpo_CPRQ and Cpo_SPTQ(1) into a copper-inducible yeast expression vector to generate heterologous expression in S. cerevisiae. We carried out assays with precursor supplementation to ensure availably of the medium-chain saturated fatty acids, i.e., lauric $\left(\mathrm{C}_{12}\right)$ and myristic acids $\left(\mathrm{C}_{14}\right)$, which are typically less abundant. Cpo_CPRQ conferred on the yeast the ability to produce a small amount of E9-12: Acyl and had no detectable activity outside of the $\mathrm{C}_{12}$ substrate (Fig. 6). Cpo_SPTQ(1) showed $\Delta 9$ desaturase activity, producing E9- and Z9-12:Acyl, Z9-14:Acyl, and Z9-16:Acyl. Double-bond positions in these products were confirmed by dimethyl disulfide (DMDS) derivatization (Fig. 6). In addition to retention times matching those of synthetic standards, spectra of the DMDS derivatives of the methyl esters displayed the following diagnostic ions: Z9-16:Me $\left(\mathrm{M}^{+}, m / z\right.$ 362; $\mathrm{A}^{+}, m / z$ 145; $\mathrm{B}^{+}, m / z$ 217), Z9$14: \mathrm{Me}\left(\mathrm{M}^{+}, m / z 334 ; \mathrm{A}^{+}, m / z 117 ; \mathrm{B}^{+}, m / z 217\right)$, and $\mathrm{E} 9-$ and Z9-12:Me $\left(\mathrm{M}^{+}, m / z\right.$ 306; $\mathrm{A}^{+}, m / z$ 89; $\left.\mathrm{B}^{+}, m / z 217\right)$. No 


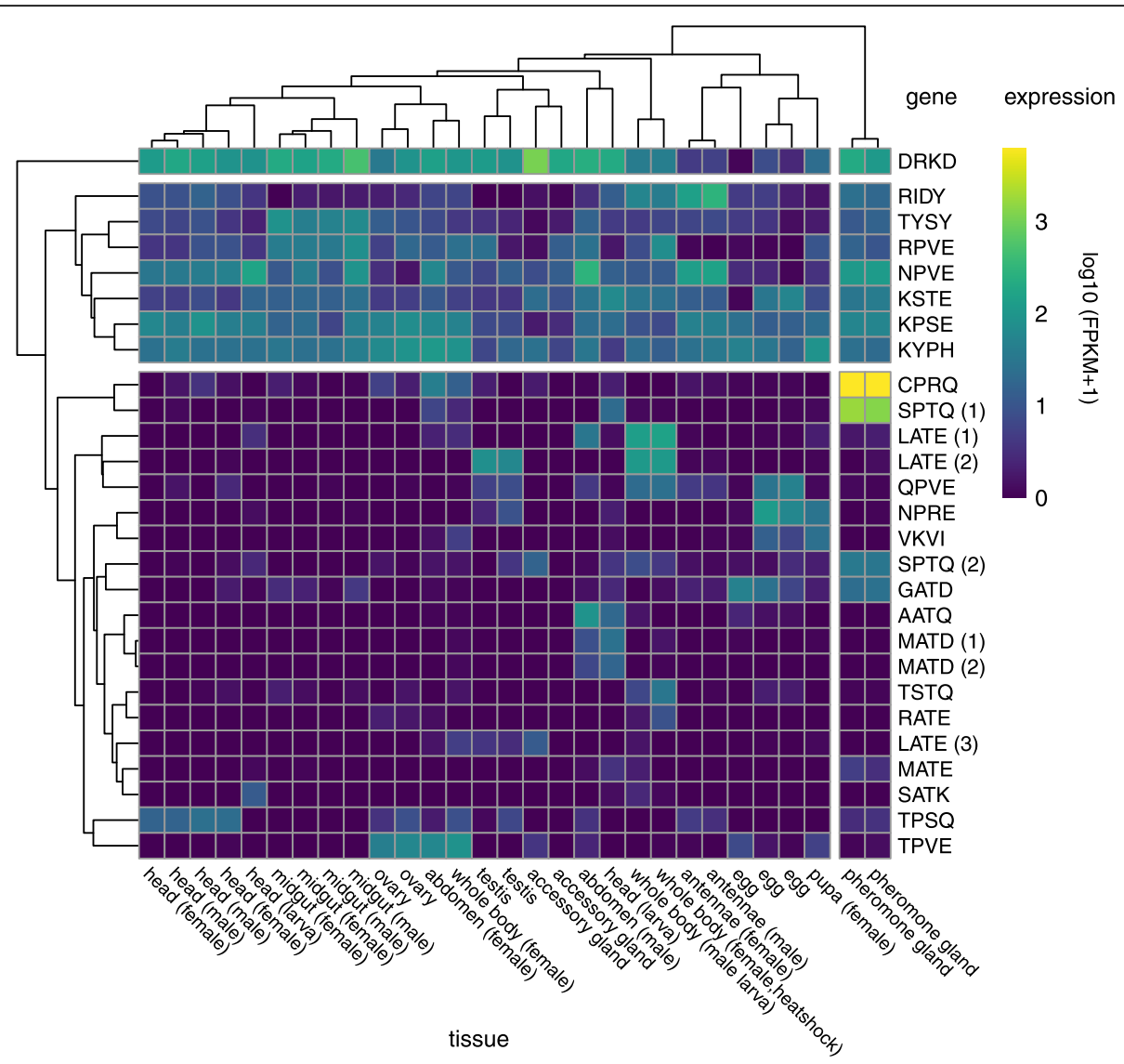

Fig. 5 Expression profiling of FAD genes in different tissues of Cydia pomonella. The heatmap represents the absolute expression value (log FPKM) of all FAD genes in the corresponding tissues. Genes are identified by their signature motif. Automatic hierarchical clustering of FAD genes distinguishes three clusters: clusters I and II contain genes with ubiquitous expression across tissues and developmental stages; cluster III contains genes with more divergent expression and higher tissue specificity. Automatic hierarchical clustering of tissues indicates that pheromone gland samples have a distinguishable profile, which is characterized by the overexpression of CPO_CPRQ and CPO_SPTQ(1). Estimates of abundance values were obtained by mapping reads against the genome. The NCBI SRA accession numbers of all RNA-Seq data sets used are given in Additional file 6: Table S4

doubly unsaturated products were detected in these experiments.

In a second round of experiments, we assayed 7 other First desaturases that could be amplified from pheromone gland cDNA. As predicted from their respective placement in the FAD phylogeny, Cpo_NPVE, CPo_KPSE, and Cpo_GATD encode $\Delta 9$ desaturases (Additional file 2: Figure S2). Cpo_NPVE is a $\Delta 9$ desaturase with preference for myristic $\left(\mathrm{C}_{14}\right)$ and palmitic $\left(\mathrm{C}_{16}\right)$ acid, showing only weak activity on lauric acid $\left(\mathrm{C}_{12}\right)$. CPo_GATD and CPo_KPSE showed $\Delta 9$ desaturase activities mainly on $C_{16}$ but also some activity on $\mathrm{C}_{14}$. The other 4 desaturases had no detectable activity in the yeast system.

Finally, we supplemented the growth medium with the monounsaturated methyl esters E9-12:Me and Z9-12: Me. The doubly unsaturated codlemone precursor, E8E10-12:Acyl, was inconsistently detected in some replicates of the assays with Cpo_CPRQ. No doubly unsaturated products were detected with the other constructs.

\section{Functional analysis identifies Cpo_CPRQ as the FAD} catalyzing $\Delta 8 \Delta 10$ desaturation

In order to evaluate the presumptive $\Delta 8 \Delta 10$ desaturase activity of CPo_CPRQ, we further investigated the activity of the enzyme in an insect cell line. We reasoned that the inconsistent activity of the enzyme in yeast could be due to the cellular environment of the expression system. When we expressed Cpo_CPRQ using the Sf9 cell system and supplementing the culture medium with lauric acid, we could observe the consistent production of E9-12 as well as E8E10-12, demonstrating that Cpo_CPRQ catalyzes the biosynthesis of E8E10-12:Acyl and its monounsaturated intermediate E9-12:Acyl (Fig. 7). As expected from the previous experiments in yeast, we did not detect activity on longer chain substrates. The retention time and mass spectrum of the E8E10-12:Me peak were identical to those of the synthetic standard. Double-bond positions of the conjugated system were confirmed by derivatization with 4-methyl-1,2,4-triazoline-3,5-dione 


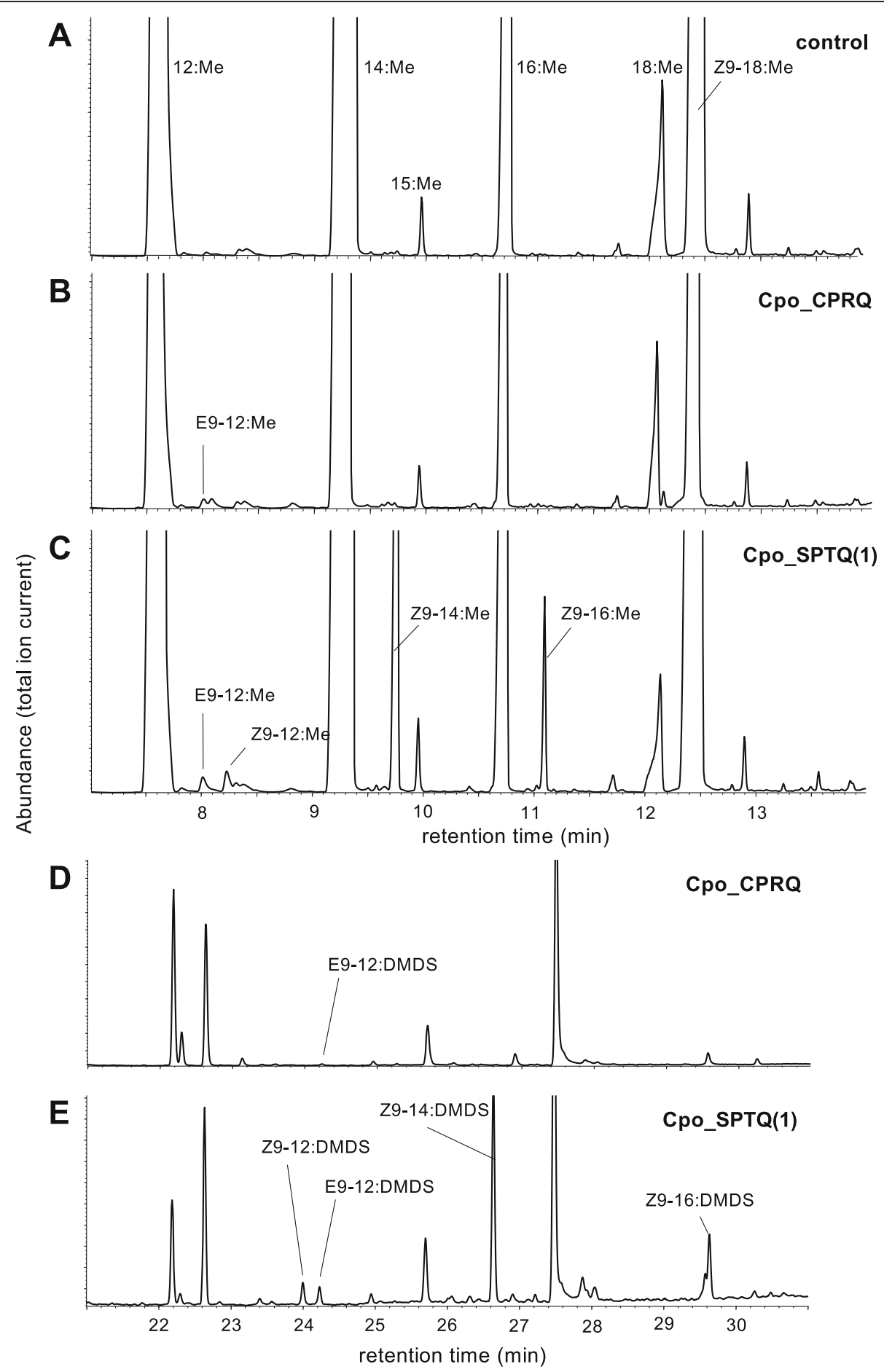

Fig. 6 Functional characterization of desaturase activity of candidate genes in yeast. Total ion chromatograms of fatty acid methyl ester (FAME) products of $\mathrm{Cu}^{2+}$-induced ole1 elo $1 \mathrm{~S}$. cerevisiae yeast supplemented with saturated acyl precursors and transformed with a empty expression vector (control), b pYEX-CHT-CPo_CPRQ, and $\mathbf{c}$ PYEX-CHT-CPo_SPTQ(1). Confirmation of the identity of enzyme products was obtained by comparison of retention time and mass spectra of synthetic standards. Confirmation of double-bond positions by mass spectra of DMDS adducts (d, e)

(MTAD) (Fig. 7). Finally, we carried out assays to further evaluate the stereospecificity of the enzyme. When provided with E9-12:Me, Cpo_CPRQ produced the doubly unsaturated product (Fig. 7). In contrast, we found no evidence for activity on the corresponding diastereomer, Z912:Me (Fig. 7). 


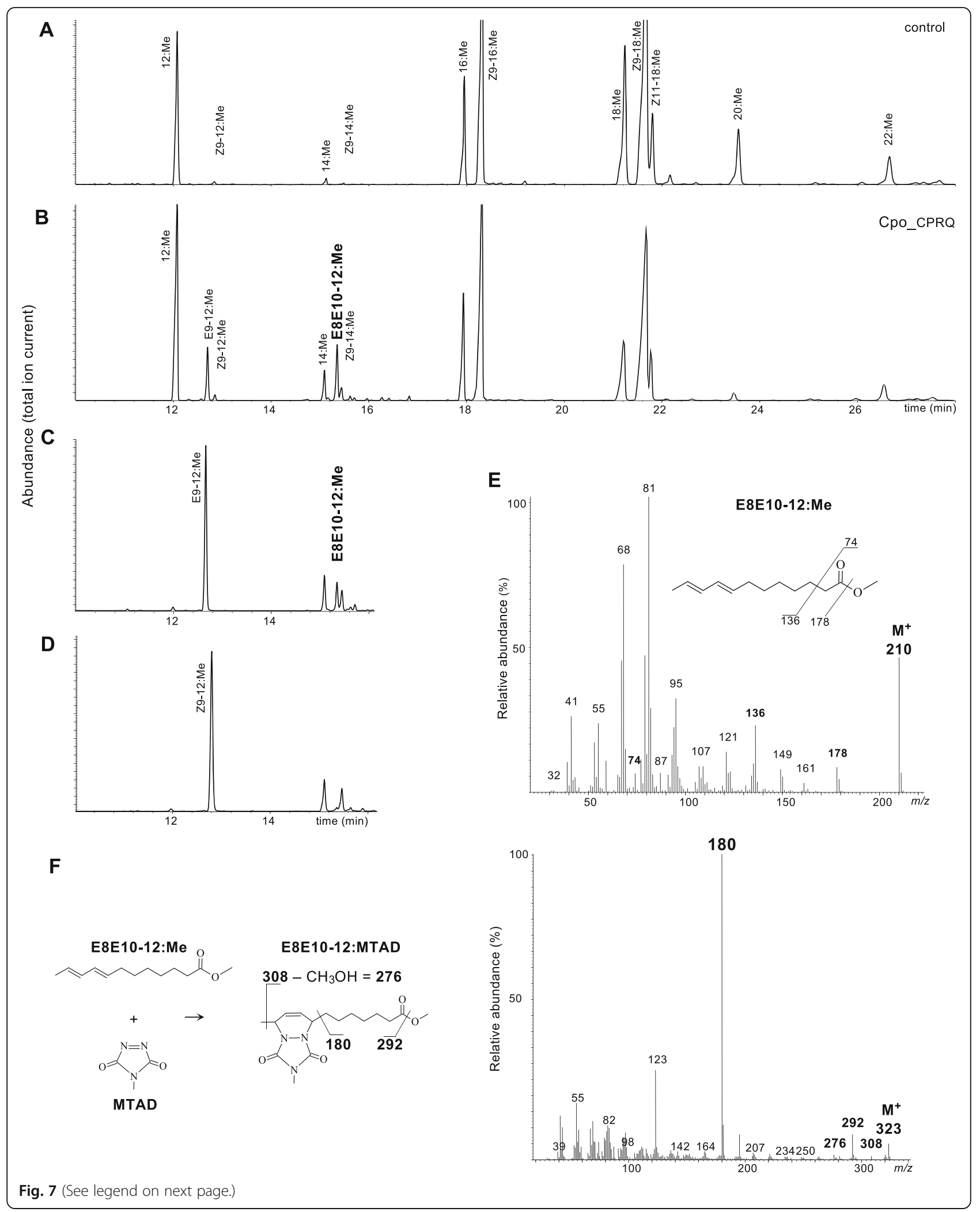


(See figure on previous page.)

Fig. 7 Functional characterization of desaturase activity of CPo_CPRQ in insect cells. Total ion chromatograms of methyl esters (FAME) samples from Sf9 cells supplemented with lauric methyl ester $\left(C_{12}\right)$ infected with a empty virus (control) or $\mathbf{b}$ recombinant baculovirus expressing CPo_CPRQ. CPo_CPRQ produces large amount of E9-12:Me and E8E10-12:Me. Sf9 insect cells infected with bacmid expressing Cpo_CPRQ in the medium in the presence of the monoenic intermediate $\mathbf{c}(E)$-9-dodecenoic methyl ester (E9-12:Me) or $\mathbf{d}$ (Z)-9-dodecenoic methyl ester (Z912:Me). The retention time and mass spectrum of the E8E10-12:Me peaks observed after addition of 12:Me and E9-12:Me were identical with those of the synthetic standard. The relatively long retention time (compound eluting later than 14:Me) is in agreement with what is expected from a diene with conjugated double bonds. e Spectrum of the E8E10-12:Me peak in $\mathbf{b}$. The relatively abundant molecular ion $\mathrm{m} / \mathrm{z} 210$ is in agreement with the expectation for a diene with conjugated double bonds. $\mathbf{f}$ Analyses of MTAD-derivatized samples displayed diagnostic ions at $\mathrm{m} / \mathrm{z} 323\left(\mathrm{M}^{+}\right), \mathrm{m} / \mathrm{z} 308$, and $\mathrm{m} / \mathrm{z} 180$ (base peak), confirming the identification of the conjugated double-bond system

Altogether, these results show that CPo_CPRQ exhibit both the ability to catalyze the trans desaturation of lauric acid to form E9-12:Acyl and the 1,4-desaturation of the latter to form the E8E10-12 conjugated pheromone precursor of codlemone.

\section{Discussion}

In this study, we show the key role of a desaturase with a dual function in the biosynthesis of codlemone. We confirm the results suggested by the labeling experiments reported by Löfstedt and Bengtsson [31] and demonstrate that Cpo_CPRQ can conduct both the initial desaturation of 12:Acyl into E9-12:Acyl, and then transform E9-12:Acyl into E8E10-12:Acyl, the immediate fatty acyl precursor of E8E10-12:OH, the sex pheromone of C. pomonella (Fig. 2). Phylogenetically, Cpo_CPRQ clusters in the Lepidoptera-specific XXXQ/E clade (Fig. 4), a lineage which encodes pheromone biosynthetic enzymes with diverse properties [34]. Several FADs found in that clade have been demonstrated to be involved in the pheromone biosynthesis of many moth species, including the species of Tortricinae using $\Delta 11$ (Epiphyas postvittana, Choristoneura rosaceana, Agryrotaenia velutinana) and $\Delta 10$ desaturations (Planotortrix octo) [20-22, 40]. Our phylogenetic reconstruction indicates that Cpo_CPRQ does not appear orthologous to any of those genes (Additional file 1: Figure S1), suggesting the recruitment of a different ancestral duplicate early in the evolution of Olethreutinae. In addition to Cpo_CPRQ, Cpo_SPTQ(1) clustered in the same clade and had a similar activity profile on lauric acid, although it produces more Z9- than E9-12:Acyl. With an expression at about $25 \%$ the level of Cpo_CPRQ, Cpo SPTQ(1) is the second most highly expressed FAD gene in the pheromone gland, a tissue in which this FAD appears exclusively expressed. Although Cpo_CPRQ appears sufficient to produce E8E10-12:Acyl, we cannot exclude the possibility that Cpo_SPTQ(1) contributes to the production of the monoene intermediate and is involved in the pheromone biosynthesis of codlemone or E9-12:OH, a pheromone component eliciting antennal response but with no apparent behavioral effect [45]. Interestingly, even though they are phylogenetically clustered within the $\Delta 11 / \Delta 10$ desaturase subfamily, Cpo_CPRQ and Cpo_SPTQ(1) exhibit primarily $\Delta 9$-desaturase activity, which likely represent the ancestral state. Whether this represents a conservation or a reversal to the ancestral function awaits further investigations. This finding provides exciting opportunities to study the structure-function relationships in FADs, in particular the structural determinant of regioselectivity.

Expansion of gene families is usually regarded as playing a key role in contributing to phenotypic diversity. The acyl-CoA desaturase gene family is characterized by a highly dynamic evolutionary history in insects $[13,14$, 34]. Bursts of gene duplication have provided many opportunities for evolution to explore protein space and generate proteins with unusual and novel functions. In moths, many examples highlight the role played by the diversification in FAD functions in allowing the expansion of the multi-dimensional chemical space available for communication via sex pheromones. Careful re-annotation of the C. pomonella genome and phylogenetic analyses of identified desaturase genes allowed us to identify 27 genes representative of all desaturase subfamilies previously identified in insects. Interestingly, all functional classes previously identified in moths (i.e., $\Delta 5, \Delta 6, \Delta 9, \Delta 10, \Delta 11, \Delta 14$ ) have homologs in C. pomonella. This indicates that FAD genes tend to be preserved in the genomes for long periods of time. The availability of several chromosome-level assemblies in Lepidoptera has revealed that the genome architecture is generally conserved, even among distant species, with few to no structural rearrangements, i.e., inversions and translocations, being observed (but see [46]). This is attested by the high level of synteny existing between $C$. pomonella and Spodoptera litura (Lepidoptera: Noctuidae), two representatives of lineages which shared their last common ancestor ca. 120 MYA [33, 47]. This stability over long evolutionary time means that we can draw tentative conclusions from the genomic organization of gene families. Specifically, the genomic location of FAD genes in C. pomonella suggests that the diversification of this gene family is ancient. First Desaturase genes from all groups sensu Helmkampf et al. [14] have representatives in species that have shared their last common ancestor over 300 MYA. Moreover, we found several expansions with differing patterns within $\Delta 9 \mathrm{C} 16>\mathrm{C} 18$ (KPSE) and the Lepidoptera-specific gene subfamily $\Delta 11$, $\Delta 10$, and bifunctional (XXXQ/E). Genes clustered in 
tandem arrays represent evolutionary recent duplications, as exemplified by the expansion in $\Delta 9 \mathrm{C} 16>\mathrm{C} 18$ (KPSE). These duplicates are likely the product of imperfect homologous recombination. By contrast, with 9 representatives spread across 6 chromosomes, the $\Delta 11 / \Delta 10$ subfamily comprises both recent duplicates (e.g., Cpo_ SPTQ(1) and Cpo_SPTQ(2)) as well as unlinked FAD genes (such as Cpo_CPRQ). The latter genes are likely to be the products of more ancient events of duplications and chromosomal rearrangements. The location of the majority of genes within this clade suggests that the diversification within this subfamily essential for the pheromone biosynthesis occurred early in the evolution of the Lepidoptera. As genome data from more species become available, it will be possible to follow the evolutionary trajectories of this gene family which has been a key contributor to pheromone evolution.

Expansion of gene families is often followed by a relaxation of selection, which translates into higher rates of fixation of mutations, including non-synonymous nucleotide substitutions $[48,49]$. Looking at the impact of selection on desaturase genes in insects, previous studies found little evidence for positive selection but rather purifying selection acting on all desaturase genes in insects, even in expanded subfamilies [14, 34]. This could be indicative that large constraints along the coding sequences to not change sites affecting the proper enzymatic function outweigh the potential for diversifying selection. Desaturases encoded by genes in the $\Delta 11$ / $\Delta 10(\mathrm{XXXQ} / \mathrm{E})$ lineages display a great variety of enzymatic functions, which are paralleled by very high levels of sequence divergence. The lack of evidence for positive selection could result from a lack of power in the statistical analysis currently available under when analyzing genes selected for very diverse properties [34]. Modification of the regulation of duplicated genes is also expected, with some paralogs specializing to a limited set of tissues or developmental stages [49]. Data from a panel representing a relatively large variety of tissue types and developmental stages reveal a large expression divergence between FAD genes. Interestingly, we see that genes present in the recent expansion (i.e., $\Delta 9$ C16>C18 (KPSE)), of which members form tandem arrays in the genome, have low to no expression in the large panel of samples we analyzed. The evidence at hand suggests that these may have limited physiological relevance. This advocates for caution when interpreting the importance and functional consequences of expansions. Some expansions can contribute to lineagespecific adaptation and an increased demand for variability in associated traits. However, it is almost certain that many expansions will not reflect a response to changes and be responsible for the evolution of novel traits but rather have their evolutionary origin in the stochastic nature of the gene duplication process. Functional testing is paramount to advance our mechanistic understanding of the proximate consequences of variation in the size of multigene families.

Previously characterized FADs that catalyze the formation of conjugated fatty acids among moth sex pheromones precursors fall into two groups: (1) double bonds can be inserted via sequential 1,2-desaturation to produce a diene, either by the action of two different desaturases operating consecutively as postulated in Dendrolimus punctatus (Lasiocampidae) [42], or by the same desaturase operating twice with an intermediate chain-shortening step as suggested for Epiphyas postvittana (Tortricidae) [20], L. capitella [41], and Spodoptera litura (Noctuidae) [50]; (2) bifunctional desaturases can introduce the first double bond and then rearrange the monoene to produce a diene with conjugated double bonds via 1,4-desaturation, as seen in Bombyx mori (Bombycidae) [43], S. littoralis (Noctuidae) [51], and Manduca sexta (Sphingidae) [44]. The C. pomonella desaturase falls into the latter category: Cpo_CPRQ introduces first an E9 double bond in the 12:Acyl saturated substrate and then transforms the $E 9$ unsaturation into the E8E10 conjugated double bonds. The independent evolution of similar features in enzymes used by distantly related species offers the opportunity to further study mechanistically the determinants of the switch between 1,2 and 1,4dehydrogenation.

Recent molecular phylogenetic studies [18, 19] provide strong support for the monophyly of Tortricinae and Olethreutinae, the two most speciose subfamilies within Tortricidae, and the paraphyly of Chlidanotinae. Our tribal-level tree for Tortricidae combined with data on moth pheromones and attractants corroborate the pattern of pheromone components in Tortricinae and Olethreutinae reviewed and discussed by Roelofs and Brown [17]. Tortricinae species use mostly 14-carbon pheromone components with unsaturation introduced via $\Delta 11$ desaturation (Fig. 8 ). Molecular and biochemical studies have confirmed the paramount role of $\Delta 11$ FADs in the pheromone biosynthesis of not only tortricines, but the vast majority of ditrysian Lepidoptera (see for instance [13, 41, 52-54]). No pheromones are reported for the Chlidanotinae. However, the sex attractants reported for three species include Z9-14:OAc and Z11-16:OAc, which supports the idea that $\Delta 11$ desaturation in combination with chain-shortening may be typical of this subfamily. By contrast, the Olethreutinae subfamily uses mainly 12 -carbon compounds. The $\Delta 9-12$ chain structures used by many species could be accounted for the action of a $\Delta 11$ enzyme producing $\Delta 11-14$ :Acyl as an intermediate following by chain-shortening to $\Delta 9-12$ : Acyl (Fig. 8). For example, the host races of the larch budworm Zeiraphera diniana (Tortricidae: Olethreutinae: Eucosmini) developing on larch (Larix decidua) or 

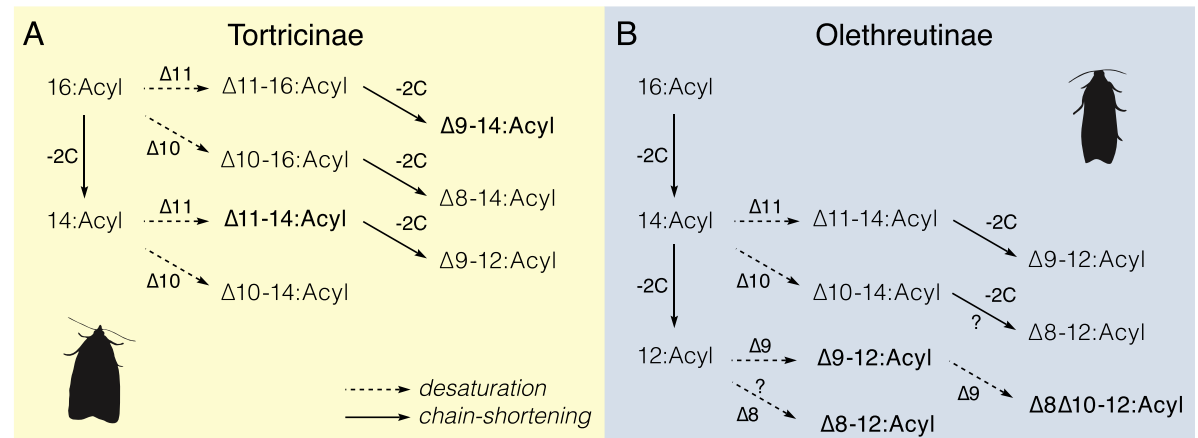

Fig. 8 Postulated biosynthetic steps to account for the typical pheromone components found in the Tortricidae. Fatty acid biosynthetic routes for sex pheromone components of Tortricinae (a) and Olethreutinae (b) are illustrated. Starting from palmitic acyl $\left(C_{16}\right)$, the pheromone precursors are produced via a combination of chain-shortening (by limited beta-oxidation) and desaturation steps. Genes encoding the fatty acyl desaturases with the postulated activities have been characterized in this study or previously, with the exception of the enzyme(s) involved in the synthesis of $\Delta 8$ monoenes in Olethreutinae

Cembra pine (Pinus cembra) used respectively E11-14: OAc and E9-12:OAc as pheromone (Guerin et al. 1984), and it is parsimonious to hypothesize that polymorphism in the activity of the chain-shortening enzyme is responsible for this difference between host races that show little to moderate genomic differentiation [55]. Our data suggest however that an alternative pathway may exist. Indeed, two of the enzymes characterized in the present study (i.e., Cpo_SPTQ(1) and CPo_CPRQ) can catalyze the production of $\Delta 9-12$ :Acyl directly from lauric acid $\left(\mathrm{C}_{12}\right)$, bypassing the need for prior $\Delta 11$ desaturation and chain-shortening (Fig. 8).

In addition to $\Delta 9-12$ chain structures, 12-carbon components with $\Delta 8$ and $\Delta 8 \Delta 10$ systems are frequently used by olethreutines. Specifically, these occur in the three major tribes: Grapholitini, Eucosmini, and Olethreutini (Fig. 1). The identification of the bifunctional desaturase catalyzing the biosynthesis of $\Delta 8 \Delta 10-12$ fatty acid derivatives sheds new light on the pathway associated with the production of pheromones of a large number of tortricids. Monounsaturated compounds with double bonds in $\Delta 8$ position frequently co-occur with conjugated $\Delta 8 \Delta 10$, including in trace amount in C. pomonella [45]. However, since we did not detect any $\Delta 8$ activity towards the lauric acid from Cpo_CPRQ or Cpo_SPTQ(1), we anticipate that a different FAD plays a role in the pheromone biosynthesis of $\Delta 8$ monoenes. This is supported by the pheromone bouquets identified for several species of olethreutines. In the podborer Matsumuraeses falcana (Tortricidae: Olethreutinae: Grapholitini), the pheromone consists of a mixture of E8-12:OAc and E8E10-12:OAc, plus minor amounts of $(E 7, Z 9)$ - and $(E 7$, $E 9)$-dodecadienyl isomers, and the monoenes E10-12: OAc and E10-14:OAc [56]. The major pheromone component in Hedya nubiferana (Tortricidae: Olethreutinae: Olethreutini) is E8E10-12:OAc, but in addition, the pheromone contains relatively large amounts of Z8- and
E8-12:OAc [57]. The same holds for Epiblema foenella (Tortricidae: Olethreutinae: Eucosmini) in which the major pheromone component was identified as Z8Z1012:OAc: in addition to the other three geometric isomers of the diene, the females produce also E8- and Z8-12: OAc but no E9-12:OAc [32]. Biosynthesis of these bouquets suggests the involvement of a FAD with $\Delta 8$ or $\Delta 10$ activity (Fig. 8). A $\Delta 10$ FAD is the key enzyme involved in the production of monounsaturated compounds with double bonds in $\Delta 8$ position. Specifically, in Planotortrix sp. and Ctenopseustis sp. (Tortricidae: Tortricinae: Archipini), Z8-14:OAc is biosynthesized via $\Delta 10$ desaturation of palmitic acid $\left(C_{16}\right)$ followed by chain-shortening, whereas the production of Z10-14: OAc involves the same FAD acting on myristic acid $\left(C_{14}\right)$ [12, 40, 58] (Fig. 8a). Our phylogenetic analysis of FAD genes shows that the C. pomonella genome contains several genes clustering with the tortricine $\Delta 10$ FADs, indicating that this biochemical activity may in theory still be carried out in olethreutines. Additional work is necessary to elucidate the routes towards the biosynthesis of monounsaturated pheromone components with double bond at even positions.

On a practical point of view, pheromones have gradually been added to the pest control toolkit. In the specific case of Cydia pomonella, in 2010, the annual production of synthetic codlemone-the codling moth pheromone-was estimated at 25 metric tons, which were used for the treatment by mating disruption of 200 , 000 ha of orchards worldwide [59]. The biological production of moth pheromones in plants or microorganisms such as yeast has been suggested as an environmentally friendly alternative to conventional chemical synthesis [60]. Beyond the stage of conceptualization, the approach is proven, and large-scale production is on the horizon [61-64]. Identification and characterization of the key enzymes underlying production of pheromone is a crucial 
step to assemble the building blocks central to the engineering of plant and cell factories. In this context, the identification and characterization of a desaturase involved in pheromone biosynthesis in C. pomonella is of particular interest, as it represents an important step towards the biological production of pheromone for the integrated pest management of several economically important olethreutines.

\section{Conclusions}

The fatty acid desaturase gene family is central to the pheromone-based communication of many insects. Our integrative approach shows that the evolution of the signature pheromone structure of olethreutine moths involved the recruitment of a gene resulting from an ancient gene duplication within a Lepidoptera-specific desaturase lineage. Members of other expanded FAD subfamilies do not appear to play a role in chemical communication. This advises for caution when postulating the consequences of lineage-specific expansions based on genomics alone.

\section{Methods}

\section{Semiochemical data set}

To compile a dataset of the semiochemicals used as sex attractants by tortricid moths, we manually retrieved data from the Pherobase, a freely accessible database of pheromones and semiochemicals which compiles information from the literature and peer-reviewed publications [65]. Altogether, we gathered data for 536 taxa belonging to the family Tortricidae. Specifically, we were interested in collecting information about the chemical structure of the bioactive fatty acyl derivatives, i.e., double-bond position and number and length of the aliphatic chain. Following the database convention, we classified bioactive compounds as pheromone or attractant. The term pheromone denotes a component of the female sex attractant, identified from females, and with demonstrated biological activity; attractant characterizes those bioactive compounds found by male responses alone, such as by systematic field screening or by significant non-target capture in traps baited with pheromone lures. Although these compounds are not necessarily used in the natural communication system, they have in most cases a high probability of being pheromone components. Details are in Additional file 3: Table S1.

\section{Molecular data set}

To infer the evolutionary relationship among the species represented in our trait dataset, we used sequence data from 137 terminal taxa in our phylogenetic analysis, including 131 species of Tortricidae as ingroup. The outgroup contained six taxa, each a species representative of Cossidae, Galacticidae, Heliocosmidae, Lacturidae,
Limacodidae, and Sesiidae, respectively. Our data set is based largely on Regier et al. [18] and Fagua et al. [19], augmented with a few additional Genbank accessions. Following the aforementioned authors, we used regions of five nuclear genes and one mitochondrial gene. The nuclear genes were carbamoyl-phosphate synthetase II (CAD), dopa decarboxylase (DDC), enolase (Eno), period (PER), and wingless (WG); the mitochondrial gene was the fragment of cytochrome oxidase I (COI) used for barcoding. Details are in Additional file 4: Table S2. For each genus, we used one representative species as the type species. Our main goal was to place the major transition in the pheromone communication system of Tortricidae and thus to infer the phylogenetic relationships with good resolution at the subfamily and tribe level. We retrieved a total of 340 Genbank accessions (see Additional file 4: Table S2 for accession numbers).

\section{Phylogenetic tree}

We concatenated the molecular data corresponding to one taxon and obtained an alignment of the entire molecular data set using MAFFT [66] as implemented in Geneious (Biomatters). The final alignment comprised 7591 sites. To define the best scheme of partitions using the MAFFT alignment, we used PartitionFinder v2.1.1 [67]. We tested models of nucleotide substitution with partitions representing codon position and genes using greedy search [68], AICC model selection, and setting the phylogeny program to phyml [69] (default value for all other settings). A 16-partition scheme was selected and used to perform the parametric phylogenetic analysis in IQ-TREE 1.6.11 [70, 71]. The maximum likelihood analysis was performed using default settings and by calculating Shimodaira-Hasegawa-like approximate ratio test (SH-aLRT) support and ultrafast bootstrap support (UFBoot [72];) after 1000 replicates each. We used the R package ggtree [73] for visualizing and annotating the phylogenetic tree with associated semiochemical data.

\section{Insects, tissue collection, and RNA-Seq}

Pupae of C. pomonella were purchased from Entomos AG (Switzerland) and were sexed upon arrival to our laboratory. Adult males and females emerged in separate jars in a climate chamber at $23 \pm 1{ }^{\circ} \mathrm{C}$ under a $16 \mathrm{~h}: 8 \mathrm{~h}$ light to dark cycle. On the third day after emergence, pheromone glands of female moths were dissected, immersed in TRIzol Reagent (Thermo Scientific), and stored at $-80^{\circ} \mathrm{C}$ until RNA extraction. Two pools of 30 glands were collected $3 \mathrm{~h}$ before and after the onset of the photophase, respectively. Total RNA was extracted according to the manufacturer's instructions. RNA concentration and purity were initially assessed on a NanoDrop2000 (Thermo Fisher Scientific). Library preparation 
and paired-end Illumina sequencing $(2 \times 100 \mathrm{bp})$ were performed by BGI (Hong Kong, PRC). We obtained $\sim 66$ million QC-passing reads per sample.

\section{Genome annotation improvements}

To ensure that all FAD genes were correctly annotated in the C. pomonella genome, we used our RNA-Seq data of pheromone gland to improve the annotation (cpom.ogs.v1.chr.gff3) which we obtained from InsectBase (http://www.insect-genome.com/cydia/). We performed low-quality base trimming and adaptor removal using cutadapt version 1.13 [74] and aligned the trimmed read pairs against the genome using HISAT2 version 2.2.0 [75]. The existing annotation was used to create a list of known splice sites using a python script distributed with HISAT2. We used StringTie version 2.1.3b [76] with the conservative transcript assembly setting to improve the annotation and reconstruct a non-redundant set of transcripts observed in any of the RNA-Seq samples. We applied Trinotate version 3.2.1 [77] to generate a functional annotation of the transcriptome data. We identified candidate FAD genes by searching for genes harboring the PFAM domain corresponding to a fatty acid desaturase type 1 domain (PF00487) in their predicted protein sequences. We used the $\mathrm{R}$ package KaryoploteR [78] to visualize the location of the FAD genes.

\section{Desaturase phylogenetic analysis}

To investigate the evolutionary relationship of the $C$. pomonella FADs, we carried out a phylogenetic analysis with other moth FAD proteins. Our sampling includes all the functional classes previously identified in moths (i.e., $\Delta 5, \Delta 6, \Delta 9, \Delta 10, \Delta 11, \Delta 14)$ and representatives of Tortricidae as well as other moth families (see Additional file 5: Table S3 for list of taxa). Protein sequences for these enzymes were downloaded from GenBank. Protein sequences for C. pomonella were predicted from the genome using gffread [79] with our improved annotation.

We aligned amino acid sequences using MAFFT version $7.427[66,80]$. We used the L-INS-i procedure and the BLOSUM30 matrix as the scoring matrix. The final multiple sequence alignment contained 114 sequences with 805 amino acid sites. The phylogenetic tree was constructed in IQ-TREE 1.6.11 [70]. An automatic model search was performed using ModelFInder [81] with the search restricted to models including the WAG, LG, and JTT substitution models. The maximum likelihood analysis was performed using default settings and by calculating Shimodaira-Hasegawa-like approximate ratio test (SH-aLRT) support and ultrafast bootstrap support (UFBoot [72];) after 1000 replicates each. We used the R package ggtree [73] for visualizing and annotating the phylogenetic tree, with midpoint rooting performed using the midpoint.root function implemented in the phytools package [82].

\section{Transcript abundance estimation}

In addition to our pheromone gland data sets, we retrieved 27 already published Illumina paired-end RNASeq data sets for C. pomonella available on the Sequence Read Archive (SRA) (see Additional file 6: Table S4 for accession numbers). These data correspond to various tissues or life stages. Following QC, low-quality base trimming, and adaptor removal with cutadapt, read pairs were aligned against the genome using HISAT2. The obtained alignment BAM files were used to estimate transcript abundance using StringTie together with our improved annotation. The abundance tables from StringTie were imported into $\mathrm{R}$ using the tximport package [83], which was used to compute gene-level abundance estimates reported as FPKM. We used the R package pheatmap [84] to visualize the expression level of FAD genes.

\section{Cloning of desaturases}

First-strand cDNAs were synthesized from $1 \mu \mathrm{g}$ of total RNA using the SuperScript IV cDNA synthesis kit (Thermo Scientific). The cDNA products were diluted to $50 \mu \mathrm{L}$. PCR amplification $(50 \mu \mathrm{L})$ was performed using $2.5 \mu \mathrm{L}$ of cDNA as template with attB-flanked genespecific primers (Additional file 7: Table S5) in a Veriti Thermo Cycler (Thermo Fisher Scientific) using Phusion polymerase master mix (Thermo Fisher Scientific). Cycling parameters were as follows: an initial denaturing step at $94{ }^{\circ} \mathrm{C}$ for $5 \mathrm{~min}, 35$ cycles at $96^{\circ} \mathrm{C}$ for $15 \mathrm{~s}, 55^{\circ} \mathrm{C}$ for $30 \mathrm{~s}, 72^{\circ} \mathrm{C}$ for $1 \mathrm{~min}$ followed by a final extension step at $72{ }^{\circ} \mathrm{C}$ for $10 \mathrm{~min}$. Specific PCR products were cloned into the pDONR221 vector (Thermo Fisher Scientific) in the presence of BP clonase (Invitrogen). Plasmid DNAs were isolated according to standard protocols and recombinant plasmids were subjected to sequencing using universal M13 primers and the BigDye terminator cycle sequencing kit v1.1 (Thermo Fisher Scientific). Sequencing products were EDTA/ethanol-precipitated, dissolved in formamide, and loaded for analysis on an in-house capillary 3130xl Genetic analyzer (Applied Biosystems).

\section{Pheromone compounds and corresponding fatty acid precursors}

All synthetic pheromone compounds used as references for identification came from our laboratory collection unless otherwise indicated. Pheromone compounds are referred to as short forms, e.g., $(E 8, E 10)$-8,10-dodecadienol is E8E10-12:OH, the corresponding acetate would be E8E10-12:OAc, corresponding acyl moiety (dodecadienoate) is E8E10-12:Acyl (although it may occur as CoA- 
derivative), and the methyl ester thereof is referred to as E8E10-12:Me. The dodecanoic methyl ester (methyl laurate, 12:Me) and tetradecanoic methyl ester (methyl myristate, 14:Me) were purchased from Larodan Fine Chemicals (Malmö, Sweden). The (E)-9-dodecenol (E9-12:OH) was purchased from Pherobank (Wageningen, The Netherlands) and then converted into the corresponding methyl ester (E9-12:Me). E8E10-12:OAc was purchased from Bedoukian (Danbury, CT, USA) and converted to the corresponding alcohol by hydrolysis using a $0.5-\mathrm{M}$ solution of $\mathrm{KOH}$ in methanol. Fatty alcohols were oxidized to the corresponding acid with pyridinium dichromate in dimethylformamide as described by Bjostad and Roelofs [85]. The methyl esters were prepared as described under fatty acid analysis (see below).

\section{Heterologous expression of desaturases in yeast}

Plasmids containing the genes of interest were selected as entry clones and subcloned into the copper-inducible pYEX-CHT vector [86]. Sequences of recombinant constructs were verified by Sanger sequencing. The pYEX-CHT recombinant expression vectors harboring C. pomonella FADs were introduced into the double deficient elo1 1 /ole1 1 strain (MATa elo1::HIS3 ole1::LEU2 ade2 his3 leu2 ura3) of the yeast Saccharomyces cerevisiae, which is defective in both desaturase and elongase functions [87] using the S.c. EasyComp Transformation kit (Thermo Fisher Scientific). For selection of uracil and leucine prototrophs, the transformed yeast was allowed to grow on an SC plate containing $0.7 \%$ YNB (w/o AA; with ammonium sulfate) and a complete drop-out medium lacking uracil and leucine (Formedium, UK), $2 \%$ glucose, $1 \%$ tergitol (type Nonidet NP-40, Sigma), $0.01 \%$ adenine (Sigma), and containing $0.5 \mathrm{mM}$ oleic acid (Sigma) as extra fatty acid source. After 4 days at $30^{\circ} \mathrm{C}$, individual colonies were selected and used to inoculate $10 \mathrm{~mL}$ selective medium, which was grown at $30^{\circ} \mathrm{C}$ at $300 \mathrm{rpm}$ in a shaking incubator for $48 \mathrm{~h}$. Yeast cultures were diluted to an $\mathrm{OD}_{600}$ of 0.4 in $10 \mathrm{~mL}$ of fresh selective medium containing $2 \mathrm{mM} \mathrm{CuSO}_{4}$ for induction, with or without addition of a biosynthetic precursor. Yeast cells contain sufficient quantities of naturally occurring palmitic acid; hence, supplementation with 16:Me was typically not necessary. Lauric acid and myristic acid were added to the medium as methyl esters (12:Me and 14:Me). In subsequent assays, the monounsaturated methyl esters E9-12:Me and Z9-12:Me were also supplemented. Each FAME precursor was prepared at a concentration of $100 \mathrm{mM}$ in $96 \%$ ethanol and added to reach a final concentration of $0.5 \mathrm{mM}$ in the culture medium. Yeasts were cultured in $30{ }^{\circ} \mathrm{C}$ with $\mathrm{Cu}^{2+}$ induction. After $48 \mathrm{~h}$, yeast cells were harvested by centrifugation at $3000 \mathrm{rpm}$ and the supernatant was discarded. The pellets were stored at $-80^{\circ} \mathrm{C}$ until fatty acid analysis.
Yeast expression experiments were conducted with three independent replicates.

\section{Heterologous expression of desaturases in insect cells}

The expression construct for CPo_CPRQ in the baculovirus expression vector system (BEVS) donor vector pDEST8_CPRQ was made by LR reaction. Recombinant bacmids were made according to instructions for the Bac-to-Bac ${ }^{\oplus}$ Baculovirus expression system given by the manufacturer (Invitrogen) using DH10EMBacY (Geneva Biotech). Baculovirus generation was done using Spodoptera frugiperda Sf9 cells (Thermo Fisher Scientific), ExCell 420 serum-free medium (Sigma), and baculoFECTIN II (OET). The virus was then amplified once to generate a P2 virus stock using Sf9 cells and Ex-Cell 420 medium. Viral titer in the P2 stock was determined using the BaculoQUANT all-in-one qPCR kit (OET) and found to be $3 \times 10^{8} \mathrm{pfu} / \mathrm{mL}$ for Cpo_CPRQ.

Insect cell lines $\mathrm{Sf} 9$ were diluted to $2 \times 10^{6}$ cells $/ \mathrm{mL}$. Heterologous expression was performed in $20-\mathrm{mL}$ cultures in Ex-Cell 420 medium and the cells infected at an MOI of 1 . The cultures were incubated in $125-\mathrm{mL}$ Erlenmeyer flasks $\left(100 \mathrm{rpm}, 27^{\circ} \mathrm{C}\right)$, with fatty acid methyl-ester substrates supplemented at a final concentration of $0.25 \mathrm{mM}$ after 1 day. After 3 days, $7.5-\mathrm{mL}$ samples were taken from the culture and centrifuged for $15 \mathrm{~min}$ at $4500 \mathrm{~g}$ at $4{ }^{\circ} \mathrm{C}$. The pellets were stored at $-80^{\circ} \mathrm{C}$ until fatty acid analysis. Sf9 expression experiments were conducted in three replicates.

\section{Fatty acid analysis}

Total lipids from cell pellets were extracted using 3.75 $\mathrm{mL}$ of methanol/chloroform $(2: 1 \mathrm{v} / \mathrm{v})$ in clear glass tubes. One milliliter of $0.15 \mathrm{M}$ acetic acid and $1.25 \mathrm{~mL}$ of water were added to wash the chloroform phase. Tubes were vortexed vigorously and centrifuged at $2000 \mathrm{rpm}$ for 2 min. The bottom chloroform phase $(\sim 1 \mathrm{~mL})$, which contains the total lipids, was transferred to a new glass tube. Fatty acid methyl esters (FAMEs) were produced from this total lipid extract. The solvent was evaporated to dryness under gentle nitrogen flow. One milliliter of sulfuric acid $2 \%$ in methanol was added to the tube, vortexed vigorously, and incubated at $90^{\circ} \mathrm{C}$ for $1 \mathrm{~h}$. After incubation, $1 \mathrm{~mL}$ of water was added and mixed well, and $1 \mathrm{~mL}$ of hexane was used to extract the FAMEs.

The methyl ester samples were subjected to GC-MS analysis on a Hewlett Packard 6890 GC (Agilent) coupled to a mass selective detector HP 5973 (Agilent). The GC was equipped with an HP-INNOWax column $(30 \mathrm{~m} \times 0.25 \mathrm{~mm} \times 0.25 \mu \mathrm{m} ;$ Agilent $)$, and helium was used as carrier gas (average velocity $33 \mathrm{~cm} / \mathrm{s}$ ). The MS was operated in electron impact mode $(70 \mathrm{eV})$, and the injector was configured in splitless mode at $220^{\circ} \mathrm{C}$. The oven temperature was set to $80^{\circ} \mathrm{C}$ for $1 \mathrm{~min}$, then 
increased at a rate of $10^{\circ} \mathrm{C} / \mathrm{min}$ up to $210^{\circ} \mathrm{C}$, followed by a hold at $210^{\circ} \mathrm{C}$ for $15 \mathrm{~min}$, and then increased at a rate of $10^{\circ} \mathrm{C} / \mathrm{min}$ up to $230^{\circ} \mathrm{C}$ followed by a hold at $230^{\circ} \mathrm{C}$ for $20 \mathrm{~min}$. The methyl esters were identified based on mass spectra and retention times in comparison with those of our collection of synthetic standards.

Double-bond positions of monounsaturated compounds were confirmed by dimethyl disulfide (DMDS) derivatization [88], followed by GC-MS analysis. FAMEs $(50 \mu \mathrm{L})$ were transferred to a new tube, $50 \mu \mathrm{L}$ DMDS were added, and the mixture was incubated at $40{ }^{\circ} \mathrm{C}$ overnight in the presence of $5 \mu \mathrm{L}$ of iodine (5\% in diethyl ether) as catalyst. Hexane $(200 \mu \mathrm{L})$ was added to the sample, and the reaction was neutralized by addition of $50-100 \mu \mathrm{L}$ sodium thiosulfate $\left(\mathrm{Na}_{2} \mathrm{~S}_{2} \mathrm{O}_{3} ; 5 \%\right.$ in water). The organic phase was recovered and concentrated under a gentle nitrogen stream to a suitable volume [41]. DMDS adducts were analyzed on an Agilent 6890 GC system equipped with a HP-5MS capillary column (30 $\mathrm{m} \times 0.25 \mathrm{~mm} \times 0.25 \mu \mathrm{m}$; Agilent) coupled with an HP 5973 mass selective detector. The oven temperature was set at $80^{\circ} \mathrm{C}$ for $1 \mathrm{~min}$, raised to $140^{\circ} \mathrm{C}$ at a rate of $20^{\circ} \mathrm{C} /$ min, then to $250^{\circ} \mathrm{C}$ at a rate of $4{ }^{\circ} \mathrm{C} / \mathrm{min}$ and held for 20 $\min [36]$.

Double-bond positions of di-unsaturated compounds with conjugated double bonds were confirmed by derivatization with 4-methyl-1,2,4-triazoline-3,5-dione (MTAD) [89]. MTAD adducts were prepared using $15 \mu \mathrm{L}$ of the methyl ester extracts transferred into a glass vial. The solvent was evaporated under gentle nitrogen flow, and $10 \mu \mathrm{L}$ of dichloromethane $\left(\mathrm{CH}_{2} \mathrm{Cl}_{2}\right)$ was added to dissolve the FAMEs. The resulting solution was treated with $10 \mu \mathrm{L}$ of MTAD (Sigma; $2 \mathrm{mg} / \mathrm{mL}$ in $\mathrm{CH}_{2} \mathrm{Cl}_{2}$ ). The reaction was ran for $10 \mathrm{~min}$ at room temperature, and $2 \mu \mathrm{L}$ was subjected to GC-MS analysis on an Agilent $6890 \mathrm{GC}$ system equipped with a HP-5MS capillary column $(30 \mathrm{~m} \times 0.25$ $\mathrm{mm} \times 0.25 \mu \mathrm{m}$; Agilent) coupled with an HP 5973 mass selective detector. The injector temperature was set to $300^{\circ} \mathrm{C}$ and the oven was set to $100^{\circ} \mathrm{C}$ and then increased by $15^{\circ} \mathrm{C} / \mathrm{min}$ up to $300^{\circ} \mathrm{C}$ followed by a hold at $300^{\circ} \mathrm{C}$ for $20 \mathrm{~min}$.

\section{Abbreviations}

FAD: Fatty acyl desaturase; FAME: Fatty acid methyl ester; DMDS: Dimethyl disulfide; MTAD: 4-Methyl-1,2,4-triazoline-3,5-dione

\section{Supplementary Information}

Supplementary information accompanies this paper at https://doi.org/10. 1186/s12915-021-01001-8.

Additional file 1: Figure S1. Phylogeny of lepidoptera FAD genes Extended version of the maximum likelihood tree displayed in Fig. 4. The tree was obtained for predicted amino acid sequence of 114 FAD genes (805 aligned positions) of 28 species, with branch support values calculated from 1000 replicates using the Shimodaira-Hasegawa-like approximate ratio test (SH_aLRT) and ultrafast bootstrapping (UFboot). Support values for branches are indicated by colored circles, with color assigned based $\mathrm{SH}-$ aLRT and UFBoot supports with $80 \%$ and $95 \%$ as thresholds of branch selec tion for SH-aLRT and UFBoot supports, respectively. The major constituent six subfamilies of First Desaturase (A1 to E) and two subfamilies of Front-End (Cyt-b5-r) and Sphingolipid Desaturases (Ifc), respectively, are indicated following the nomenclature proposed by Helmkampf et al. (2015). For First Desaturases, the different shades correspond to the indicated putative biochemical activities and consensus signature motif (if any). Triangles indicate sequences from C. pomonella. The scale bar represents 0.5 substitutions per amino acid position. Species are indicated by three- or four-letter prefixes (see Additional file 5: Table S3 for details). Biochemical activities (or signature motif) are indicated after the abbreviated species name, followed by accession number in parenthesis.

Additional file 2: Figure S2. Functional characterization of desaturase activity of First-desaturases. Total ion chromatograms of fatty acid methyl ester (FAME) products of $\mathrm{Cu}^{2+}$-induced ole l elo1 S. cerevisae yeast supplemented with saturated acyl precursors and transformed with (A \& C) empty expression vector (control), (B) pYEX-CHT-Cpo_NPVE, (D) pYEXCHT-CPo_KPSE, and (E) pYEX-CHT-CPo_GATD.

Additional file 3: Table S1. List of terminal taxa and corresponding bioactivity data used in this study.

Additional file 4: Table S2. List of terminal taxa and corresponding GenBank accession numbers used in this study.

Additional file 5: Table S3. List of species represented in the FAD phylogeny.

Additional file 6: Table S4. List of SRA accessions corresponding to RNA-Seq data sets for Cydia pomonella.

Additional file 7: Table S5. Primer sequences used for amplification and cloning of desaturase genes.

\section{Acknowledgements}

We thank Wendell Roelofs for his comments on an earlier version of this manuscript and the Lund Protein Production Platform (LP3) for technical support and advice on the expression in insect cell lines. The computations in this paper were run on the FASRC Cannon cluster supported by the FAS Division of Science Research Computing Group at Harvard University.

\section{Authors' contributions}

$J M L, B J D$, and $C L$ designed the research; BJD collected tissue and processed samples for RNA-Seq; JML performed analyses related to phylogenetics and bioinformatics; BJD performed functional assays and chemical analyses; JML prepared the figures; JML wrote the paper with input from BJD and CL. All authors read and approved the final manuscript.

\section{Funding}

This project has received funding from the European Union's Horizon 2020 research and innovation programme (grant agreement no. 760798, Olefine) (CL), the Swedish Foundation for Strategic Research (grant no. RBP 14-0037, Oil Crops for the Future) (CL), the Swedish Research Council (CL), Formas $(\mathrm{CL})$, and the Royal Physiographic Society in Lund (JML). Open Access funding provided by Lund University.

\section{Availability of data and materials}

All data generated or analyzed during this study are included in this published article and its supplementary information files.

\section{Declarations}

Ethics approval and consent to participate Not applicable

\section{Consent for publication}

Not applicable

\section{Competing interests}

The authors declare the following competing interests: $C L$ is a founder of SemioPlant AB; BJD and CL have filed patents related to the use of CPo_CPRQ for pheromone production. JML declares that he has no competing interests. 


\section{Author details}

'Department of Biology, Lund University, Sölvegatan 37, SE-223 62 Lund, Sweden. ${ }^{2}$ Department of Organismic and Evolutionary Biology, Harvard University, 16 Divinity Avenue, Cambridge, MA 02138, USA.

\section{Received: 20 December 2020 Accepted: 7 March 2021}

\section{Published online: 23 April 2021}

\section{References}

1. Lespinet $\mathrm{O}$, Wolf $\mathrm{Yl}$, Koonin EV, Aravind L. The role of lineage-specific gene family expansion in the evolution of eukaryotes. Genome Res. 2002;12(7): 1048-59. https://doi.org/10.1101/gr.174302.

2. Hahn MW, Bie TD, Stajich JE, Nguyen C, Cristianini N. Estimating the tempo and mode of gene family evolution from comparative genomic data. Genome Res. 2005:15(8):1153-60. https://doi.org/10.1101/gr.3567505.

3. Hahn MW, Han MV, Han S-G. Gene family evolution across 12 Drosophila genomes. PLoS Genet. 2007;3(11):e197. https://doi.org/10.13 71/journal.pgen.0030197.

4. Butenandt A, Beckmann R, Stamm D, Hecker E. Uber den Sexual-Lockstoff des Seidenspinners Bombyx mori - Reindarstellung und Konstitution. Z Natforsch B. 1959;14(4):283-4

5. Löfstedt C, Wahlberg N, Millar JM. Evolutionary patterns of pheromone diversity in Lepidoptera. In: Allison JD, Cardé RT, editors. Pheromone communication in moths: evolution, behavior and application. Berkeley: University of California Press; 2016. p. 43-82.

6. Tillman JA, Seybold SJ, Jurenka RA, Blomquist GJ. Insect pheromones-an overview of biosynthesis and endocrine regulation. Insect Biochem Mol Biol. 1999;29(6):481-514. https://doi.org/10.1016/S0965-1748(99)00016-8.

7. Sperling P, Ternes P, Zank TK, Heinz E. The evolution of desaturases. Prostaglandins Leukot Essent Fatty Acids. 2003;68(2):73-95. https://doi.org/1 0.1016/S0952-3278(02)00258-2.

8. Takahashi A, Tsaur S-C, Coyne JA, Wu C-I. The nucleotide changes governing cuticular hydrocarbon variation and their evolution in Drosophila melanogaster. Proc Natl Acad Sci U S A. 2001;98(7):3920-5. https://doi.org/1 0.1073/pnas.061465098.

9. Roelofs WL, Liu W, Hao G, Jiao H, Rooney AP, Linn CE. Evolution of moth sex pheromones via ancestral genes. Proc Natl Acad Sci U S A. 2002;99(21): 13621-6. https://doi.org/10.1073/pnas.152445399.

10. Fang S, Ting C-T, Lee C-R, Chu K-H, Wang C-C, Tsaur S-C. Molecular evolution and functional diversification of fatty acid desaturases after recurrent gene duplication in Drosophila. Mol Biol Evol. 2009;26(7):1447-56. https://doi.org/10.1093/molbev/msp057.

11. Shirangi TR, Dufour HD, Williams TM, Carroll SB. Rapid evolution of sex pheromone-producing enzyme expression in Drosophila. PLoS Biol. 2009; 7(8):e1000168. https://doi.org/10.1371/journal.pbio.1000168.

12. Albre J, Liénard MA, Sirey TM, Schmidt S, Tooman LK, Carraher C, Greenwood DR, Löfstedt C, Newcomb RD. Sex pheromone evolution is associated with differential regulation of the same desaturase gene in two genera of leafroller moths. PLoS Genet. 2012;8(1):e1002489. https://doi.org/1 0.1371/journal.pgen.1002489.

13. Roelofs WL, Rooney AP. Molecular genetics and evolution of pheromone biosynthesis in Lepidoptera. Proc Natl Acad Sci U S A. 2003;100(16):9179-84. https://doi.org/10.1073/pnas.1233767100a.

14. Helmkampf M, Cash E, Gadau J. Evolution of the insect desaturase gene family with an emphasis on social hymenoptera. Mol Biol Evol. 2015;32(2): 456-71. https://doi.org/10.1093/molbev/msu315.

15. Roe AD, Weller SJ, Baixeras J, Brown J, Cummings MP, Davis D, Kawahara AY, Parr C, Regier JC, Rubinoff D. Evolutionary framework for Lepidoptera model systems. Genetics and Molecular Biology of Lepidoptera. Boca Raton: CRC Press; 2009. p. 1-24

16. Gilligan TM, Baixeras J, Brown JW. T@RTS: online world catalogue of the Tortricidae (Ver. 4.0); 2018.

17. Roelofs WL, Brown RL. Pheromones and evolutionary relationships of Tortricidae. Annu Rev Ecol Syst. 1982;13(1):395-422. https://doi.org/10.114 6/annurev.es.13.110182.002143

18. Regier JC, Brown JW, Mitter C, Baixeras J, Cho S, Cummings MP, Zwick A. A molecular phylogeny for the leaf-roller moths (Lepidoptera: Tortricidae) and its implications for classification and life history evolution. PLoS One. 2012; 7(4):e35574. https://doi.org/10.1371/journal.pone.0035574.

19. Fagua G, Condamine FL, Horak M, Zwick A, Sperling FAH. Diversification shifts in leafroller moths linked to continental colonization and the rise of angiosperms. Cladistics. 2017;33(5):449-66 https://doi.org/10.1111/cla.12185.

20. Liu W, Jiao H, Murray NC, O'Connor M, Roelofs WL. Gene characterized for membrane desaturase that produces (E)-11 isomers of mono- and diunsaturated fatty acids. Proc Natl Acad Sci U S A. 2002;99(2):620-4. https:// doi.org/10.1073/pnas.221601498.

21. Liu W, Jiao H, O'Connor M, Roelofs WL. Moth desaturase characterized that produces both $\mathrm{Z}$ and $\mathrm{E}$ isomers of $\Delta 11$-tetradecenoic acids. Insect Biochem Mol Biol. 2002;32(11):1489-95. https://doi.org/10.1016/S0965-1748(02)00069-3.

22. Hao G, O'Connor M, Liu W, Roelofs WL. Characterization of Z/E11- and Z9desaturases from the obliquebanded leafroller moth, Choristoneura rosaceana. J Insect Sci. 2002;2(1):26.

23. Witzgall $P$, Stelinski L, Gut L, Thomson D. Codling moth management and chemical ecology. Annu Rev Entomol. 2008;53(1):503-22. https://doi.org/1 0.1146/annurev.ento.53.103106.093323.

24. Roelofs W, Comeau A, Hill A, Milicevic G. Sex attractant of the codling moth: characterization with electroantennogram technique. Science. 1971; 174(4006):297-9. https://doi.org/10.1126/science.174.4006.297.

25. Beroza M, Bierl BA, Moffitt HR. Sex pheromones: (E,E)-8,10-dodecadien-1-ol in the codling moth. Science. 1974;183(4120):89-90. https://doi.org/10.1126/ science.183.4120.89.

26. McDonough LM, Moffitt HR. Sex pheromone of the codling moth. Science. 1974;183(4128):978.

27. Arn H, Guerin PM, Buser HR, Rauscher S, Mani E. Sex pheromone blend of the codling moth, Cydia pomonella: evidence for a behavioral role of dodecan-1-ol. Experientia. 1985;41(11):1482-4. https://doi.org/10.1007/BF01950048.

28. Yamaoka R, Taniquchi Y, Hayashiya K. Bombykol biosynthesis from deuterium-labeled (Z)-11-hexadecenoic acid. Experientia. 1984:40(1):80-1. https://doi.org/10.1007/BF01959112.

29. Tumlinson $\mathrm{JH}$, Teal PEA, Fang $\mathrm{N}$. The integral role of triacyl glycerols in the biosynthesis of the aldehydic sex pheromones of Manduca sexta (L. ). Biorg Med Chem. 1996:4(3):451-60. https://doi.org/10.1016/09680896(96)00025-9.

30. Navarro I, Mas E, Fabriàs G, Camps F. Identification and biosynthesis of $(E, E)$ 10,12-tetradecadienyl acetate in Spodoptera littoralis female sex pheromone gland. Biorg Med Chem. 1997;5(7):1267-74. https://doi.org/10.1016/S09680896(97)00072-2.

31. Löfstedt $C$, Bengtsson M. Sex pheromone biosynthesis of (E,E)-8,10dodecadienol in codling moth Cydia pomonella involves E9 desaturation. J Chem Ecol. 1988;14(3):903-15. https://doi.org/10.1007/BF01018782.

32. Witzgall $P$, Chambon J-P, Bengtsson M, Unelius CR, Appelgren M, Makranczy G, Muraleedharan N, Reed DW, Hellrigl K, Buser H-R, Hallberg E, Bergström G, Tóth M, Löfstedt C, Löfqvist J. Sex pheromones and attractants in the Eucosmini and Grapholitini (Lepidoptera, Tortricidae). Chemoecology. 1996; 7(1):13-23. https://doi.org/10.1007/BF01240633.

33. Wan F, Yin C, Tang R, Chen M, Wu Q, Huang C, Qian W, Rota-Stabelli O, Yang N, Wang S, Wang G, Zhang G, Guo J, Gu L(A), Chen L, Xing L, Xi Y, Liu F, Lin K, Guo M, Liu W, He K, Tian R, Jacquin-Joly E, Franck P, Siegwart M, Ometto L, Anfora G, Blaxter M, Meslin C, Nguyen P, Dalíková M, Marec F. Olivares J, Maugin S, Shen J, Liu J, Guo J, Luo J, Liu B, Fan W, Feng L, Zhao X, Peng X, Wang K, Liu L, Zhan H, Liu W, Shi G, Jiang C, Jin J, Xian X, Lu S, Ye M, Li M, Yang M, Xiong R, Walters JR, Li F. A chromosome-level genome assembly of Cydia pomonella provides insights into chemical ecology and insecticide resistance. Nat Commun. 2019;10(1):4237. https://doi.org/10.103 8/s41467-019-12175-9

34. Knipple DC, Rosenfield C-L, Nielsen R, You KM, Jeong SE. Evolution of the integral membrane desaturase gene family in moths and flies. Genetics. 2002:162(4):1737-52

35. Lassance J-M, Löfstedt C. Concerted evolution of male and female display traits in the European corn borer, Ostrinia nubilalis. BMC Biol. 2009;7(1):10.

36. Wang $\mathrm{H}-\mathrm{L}$, Liénard MA, Zhao C-H, Wang C-Z, Löfstedt C. Neofunctionalization in an ancestral insect desaturase lineage led to rare $\Delta 6$ pheromone signals in the Chinese tussah silkworm. Insect Biochem Mol Biol. 2010:40(10):742-51. https://doi.org/10.1016/j.ibmb.2010.07.009.

37. Hagström ÅK, Albre J, Tooman LK, Thirmawithana AH, Corcoran J, Löfstedt C, Newcomb RD. A novel fatty acyl desaturase from the pheromone glands of Ctenopseustis obliquana and C. herana with specific Z5-desaturase activity on myristic acid. J Chem Ecol. 2014:40(1):63-70. https://doi.org/10.1007/s1 0886-013-0373-1.

38. Liu W, Rooney AP, Xue B, Roelofs WL. Desaturases from the spotted fireworm moth (Choristoneura parallela) shed light on the evolutionary 
origins of novel moth sex pheromone desaturases. Gene. 2004;342(2):30311. https://doi.org/10.1016/j.gene.2004.08.017.

39. Lu F, Wei Z, Luo Y, Guo H, Zhang G, Xia Q, Wang Y. SilkDB 3.0: visualizing and exploring multiple levels of data for silkworm. Nucleic Acids Res. 2020; 48(D1):D749-D55. https://doi.org/10.1093/nar/gkz919.

40. Hao G, Liu W, O'Connor M, Roelofs WL. Acyl-CoA Z9- and Z10-desaturase genes from a New Zealand leafroller moth species, Planotortrix octo. Insect Biochem Mol Biol. 2002;32(9):961-6. https://doi.org/10.1016/S0965-1748(01 )00176-X.

41. Liénard MA, Strandh M, Hedenström E, Johansson T, Löfstedt C. Key biosynthetic gene subfamily recruited for pheromone production prior to the extensive radiation of Lepidoptera. BMC Evol Biol. 2008;8(1):270. https:// doi.org/10.1186/1471-2148-8-270.

42. Liénard MA, Lassance J-M, Wang H-L, Zhao C-H, Piskur J, Johansson T, Löfstedt C. Elucidation of the sex-pheromone biosynthesis producing 5,7dodecadienes in Dendrolimus punctatus (Lepidoptera: Lasiocampidae) reveals $\Delta 11$ - and $\Delta 9$-desaturases with unusual catalytic properties. Insect Biochem Mol Biol. 2010;40(6):440-52. https://doi.org/10.1016/j.ibmb.2010.04. 003.

43. Moto K, Suzuki MG, Hull JJ, Kurata R, Takahashi S, Yamamoto M, Okano K, Imai $\mathrm{K}$, Ando $\mathrm{T}$, Matsumoto $\mathrm{S}$. Involvement of a bifunctional fatty-acyl desaturase in the biosynthesis of the silkmoth, Bombyx mori, sex pheromone. Proc Natl Acad Sci U S A. 2004;101(23):8631-6. https://doi.org/1 0.1073/pnas.0402056101.

44. Matoušková P, Pichová I, Svatoš A. Functional characterization of a desaturase from the tobacco hornworm moth (Manduca sexta) with bifunctional Z11- and 10,12-desaturase activity. Insect Biochem Mol Biol. 2007;37(6):601-10. https://doi.org/10.1016/j.ibmb.2007.03.004.

45. Witzgall P, Bengtsson M, Rauscher S, Liblikas I, Bäckman A-C, Coracini M, Anderson $\mathrm{P}$, Löfqvist J. Identification of further sex pheromone synergists in the codling moth, Cydia pomonella. Entomol Exp Appl. 2001;101(2):131-41. https://doi.org/10.1046/j.1570-7458.2001.00898.x.

46. Hill J, Rastas P, Hornett EA, Neethiraj R, Clark N, Morehouse N, CelorioMancera MdIP, Cols JC, Dircksen H, Meslin C, Keehnen N, Pruisscher P, Sikkink K, Vives M, Vogel H, Wiklund C, Woronik A, Boggs CL, Nylin S, Wheat CW. Unprecedented reorganization of holocentric chromosomes provides insights into the enigma of lepidopteran chromosome evolution. Sci Adv. 2019;5(6):eaau3648.

47. Kawahara AY, Plotkin D, Espeland M, Meusemann K, Toussaint EFA, Donath A, Gimnich F, Frandsen PB, Zwick A, dos Reis M, Barber JR, Peters RS, Liu S, Zhou X, Mayer C, Podsiadlowski L, Storer C, Yack JE, Misof B, Breinholt JW. Phylogenomics reveals the evolutionary timing and pattern of butterflies and moths. Proc Natl Acad Sci U S A. 2019;1 16(45):22657-63. https://doi. org/10.1073/pnas.1907847116.

48. Bielawski JP, Yang Z. Maximum likelihood methods for detecting adaptive evolution after gene duplication. In: Meyer A, Van de Peer Y, editors. Genome evolution: gene and genome duplications and the origin of novel gene functions. Dordrecht: Springer Netherlands; 2003. p. 201-12. https:// doi.org/10.1007/978-94-010-0263-9_20.

49. Taylor JS, Raes J. Duplication and divergence: the evolution of new genes and old ideas. Annu Rev Genet. 2004;38(1):615-43. https://doi.org/10.1146/a nnurev.genet.38.072902.092831.

50. Xia Y-H, Zhang Y-N, Ding B-J, Wang H-L, Löfstedt C. Multi-functional desaturases in two Spodoptera moths with $\Delta 11$ and $\Delta 12$ desaturation activities. J Chem Ecol. 2019;45(4):378-87. https://doi.org/10.1007/s10886-01 9-01067-3.

51. Serra M, Piña B, Bujons J, Camps F, Fabriàs G. Biosynthesis of 10,12-dienoic fatty acids by a bifunctional $\Delta 11$ desaturase in Spodoptera littoralis. Insect Biochem Mol Biol. 2006;36(8):634-41. https://doi.org/10.1016/j.ibmb.2006.05.005.

52. Jurenka RA. Biochemistry of female moth sex pheromones. In: Blomquist GJ, Vogt R, editors. Insect pheromone biochemistry and molecular biology. The biosynthesis and detection of pheromones and plant volatiles; 2003. p. 53-80.

53. Liénard MA, Wang H-L, Lassance J-M, Löfstedt C. Sex pheromone biosynthetic pathways are conserved between moths and the butterfly Bicyclus anynana. Nat Commun. 2014;5(1):3957. https://doi.org/10.1038/ ncomms4957.

54. Liénard MA, Löfsted C. Functional flexibility as a prelude to signal diversity? Role of a fatty acyl reductase in moth pheromone evolution. Commun Integr Biol. 2010;3(6):586-8. https://doi.org/10.4161/cib.3.6.13177.
55. Emelianov I, Marec F, Mallet J. Genomic evidence for divergence with gene flow in host races of the larch budmoth. Proc R Soc Lond B Biol Sci. 2004; 271(1534):97-105. https://doi.org/10.1098/rspb.2003.2574.

56. Wakamura S. Identification of sex-pheromone components of the podborer, Matsumuraeses falcana (Walshingham) (Lepidoptera: Tortricidae). Appl Entomol Zool. 1985;20(2):189-98. https://doi.org/10.1303/aez.20.189.

57. Frerot B, Priesner E, Gallois M. A sex attractant for the green budworm moth, Hedya nubiferana. Z Naturforsch C J Biosci. 1979;34(12):1248-52. https://doi.org/10.1515/znc-1979-1229.

58. Foster SP, Roelofs WL. Sex pheromone differences in populations of the brownheaded leafroller, Ctenopseustis obliquana. J Chem Ecol. 1987;13(3): 623-9. https://doi.org/10.1007/BF01880104.

59. Witzgall P, Kirsch P, Cork A. Sex pheromones and their impact on pest management. J Chem Ecol. 2010;36(1):80-100. https://doi.org/10.1007/s1 0886-009-9737-y.

60. Löfstedt C, Xia Y-H. Biological production of insect pheromones in cell and plant factories. In: Blomquist GJ, Vogt RG, editors. Insect pheromone biochemistry and molecular biology. 2nd ed. London: Academic; 2021. p. 89-121. https://doi.org/10.1016/B978-0-12-819628-1.00003-1.

61. Nešněrová P, Šebek P, Macek T, Svatoš A. First semi-synthetic preparation of sex pheromones. Green Chem. 2004;6(7):305-7. https://doi.org/10.1039/B4 06814A.

62. Hagström ÅK, Wang H-L, Liénard MA, Lassance J-M, Johansson T, Löfstedt C. A moth pheromone brewery: production of (Z)-11-hexadecenol by heterologous co-expression of two biosynthetic genes from a noctuid moth in a yeast cell factory. Microb Cell Factories. 2013;12(1):125. https://doi.org/1 $0.1186 / 1475-2859-12-125$.

63. Ding B-J, Hofvander P, Wang H-L, Durrett TP, Stymne S, Löfstedt C. A plant factory for moth pheromone production. Nat Commun. 2014;5(1):3353. https://doi.org/10.1038/ncomms4353.

64. Holkenbrink C, Ding B-J, Wang H-L, Dam MI, Petkevicius K, Kildegaard KR, Wenning L, Sinkwitz C, Lorántfy B, Koutsoumpeli E, França L, Pires M, Bernardi C, Urrutia W, Mafra-Neto A, Ferreira BS, Raptopoulos D, Konstantopoulou M, Löfstedt C, Borodina I. Production of moth sex pheromones for pest control by yeast fermentation. Metab Eng. 2020;62: 312-21. https://doi.org/10.1016/.ymben.2020.10.001.

65. El-Sayed AM. The Pherobase: database of pheromones and semiochemicals; 2020. https://www.pherobase.com/.

66. Katoh K, Misawa K, Kuma K-I, Miyata T. MAFFT: a novel method for rapid multiple sequence alignment based on fast Fourier transform. Nucleic Acids Res. 2002;30(14):3059-66. https://doi.org/10.1093/nar/gkf436.

67. Lanfear R, Frandsen PB, Wright AM, Senfeld T, Calcott B. PartitionFinder 2: new methods for selecting partitioned models of evolution for molecular and morphological phylogenetic analyses. Mol Biol Evol. 2017;34(3):772-3. https://doi.org/10.1093/molbev/msw260.

68. Lanfear R, Calcott B, Ho SYW, Guindon S. PartitionFinder: combined selection of partitioning schemes and substitution models for phylogenetic analyses. Mol Biol Evol. 2012;29(6):1695-701. https://doi.org/10.1093/ molbev/mss020.

69. Guindon S, Dufayard J-F, Lefort V, Anisimova M, Hordijk W, Gascuel O. New algorithms and methods to estimate maximum-likelihood phylogenies: assessing the performance of PhyML 3.0. Syst Biol. 2010;59(3):307-21. https://doi.org/10.1093/sysbio/syq010.

70. Nguyen L-T, Schmidt HA, von Haeseler A, Minh BQ. IQ-TREE: a fast and effective stochastic algorithm for estimating maximum-likelihood phylogenies. Mol Biol Evol. 2015;32(1):268-74. https://doi.org/10.1093/ molbev/msu300.

71. Chernomor O, von Haeseler A, Minh BQ. Terrace aware data structure for phylogenomic inference from supermatrices. Syst Biol. 2016;65(6):997-1008. https://doi.org/10.1093/sysbio/syw037.

72. Hoang DT, Chernomor O, von Haeseler A, Minh BQ, Vinh LS. UFBoot2: improving the ultrafast bootstrap approximation. Mol Biol Evol. 2018;35(2): 518-22. https://doi.org/10.1093/molbev/msx281.

73. Yu G, Smith DK, Zhu H, Guan Y, Lam TT-Y. ggtree: an r package for visualization and annotation of phylogenetic trees with their covariates and other associated data. Methods Ecol Evol. 2017;8(1):28-36. https://doi.org/1 $0.1111 / 2041-210 X .12628$

74. Martin M. Cutadapt removes adapter sequences from high-throughput sequencing reads. EMBnet J. 2011;17(1):10-2. https://doi.org/10.14806/ej.1 7.1.200. 
75. Kim D, Paggi JM, Park C, Bennett C, Salzberg SL. Graph-based genome alignment and genotyping with HISAT2 and HISAT-genotype. Nat Biotechnol. 2019;37(8):907-15. https://doi.org/10.1038/s41587-019-0201-4.

76. Pertea M, Pertea GM, Antonescu CM, Chang T-C, Mendell JT, Salzberg SL. StringTie enables improved reconstruction of a transcriptome from RNA-seq reads. Nat Biotechnol. 2015;33(3):290-5. https://doi.org/10.1038/nbt.3122.

77. Bryant DM, Johnson K, DiTommaso T, Tickle T, Couger MB, Payzin-Dogru D, Lee TJ, Leigh ND, Kuo TH, Davis FG, Bateman J, Bryant S, Guzikowski AR, Tsai SL, Coyne S, Ye WW, Freeman RM Jr, Peshkin L, Tabin CJ, Regev A, Haas BJ, Whited JL. A tissue-mapped axolotl de novo transcriptome enables identification of limb regeneration factors. Cell Rep. 2017;18(3):762-76. https://doi.org/10.1016/j.celrep.2016.12.063.

78. Gel B, Serra E. karyoploteR: an R/Bioconductor package to plot customizable genomes displaying arbitrary data. Bioinformatics. 2017;33(19):3088-90. https://doi.org/10.1093/bioinformatics/btx346.

79. Pertea G, Pertea M. GFF utilities: GffRead and GffCompare. F1000Res. 2020;9:304.

80. Katoh K, Standley DM. MAFFT multiple sequence alignment software version 7: improvements in performance and usability. Mol Biol Evol. 2013; 30(4):772-80. https://doi.org/10.1093/molbev/mst010.

81. Kalyaanamoorthy S, Minh BQ, Wong TKF, von Haeseler A, Jermiin LS ModelFinder: fast model selection for accurate phylogenetic estimates. Nat Methods. 2017;14(6):587-9. https://doi.org/10.1038/nmeth.4285.

82. Revell L. phytools: an R package for phylogenetic comparative biology (and other things). Methods Ecol Evol. 2012;3(2):217-23. https://doi.org/1 0.1111/j.2041-210X.2011.00169.x.

83. Soneson C, Love MI, Robinson MD. Differential analyses for RNA-seg: transcript-level estimates improve gene-level inferences. F1000Res. 2016:4:1521.

84. Kolde R. pheatmap: pretty heatmaps. 1.0.12 ed. 2019

85. Bjostad LB, Roelofs WL. Sex pheromone biosynthetic precursors in Bombyx mori. Insect Biochem Mol Biol. 1984;14:275-8. https://doi.org/10.1016/0020-1 790(84)90060-X.

86. Patel O, Fernley R, Macreadie I. Saccharomyces cerevisiae expression vectors with thrombin-cleavable $\mathrm{N}$ - and C-terminal 6x(His) tags. Biotechnol Lett. 2003;25(4):331-4. https://doi.org/10.1023/A:1022384828795.

87. Schneiter R, Tatzer V, Gogg G, Leitner E, Kohlwein SD. Elo1p-dependent carboxy-terminal elongation of $\mathrm{C} 14: 1 \Delta 9$ to $\mathrm{C} 16: 1 \Delta 11$ fatty acids in Saccharomyces cerevisiae. J Bacteriol. 2000;182(13):3655-60. https://doi.org/1 0.1128/JB.182.13.3655-3660.2000.

88. Buser HR, Arn H, Guerin P, Rauscher S. Determination of double bond position in mono-unsaturated acetates by mass spectrometry of dimethyl disulfide adducts. Anal Chem. 1983;55(6):818-22. https://doi.org/10.1021/a c00257a003.

89. Marques FA, Millar JG, McElfresh JS. Efficient method to locate double bond positions in conjugated trienes. J Chromatogr A. 2004;1048(1):59-65. https:// doi.org/10.1016/S0021-9673(04)01147-1.

\section{Publisher's Note}

Springer Nature remains neutral with regard to jurisdictional claims in published maps and institutional affiliations.

Ready to submit your research? Choose BMC and benefit from:

- fast, convenient online submission

- thorough peer review by experienced researchers in your field

- rapid publication on acceptance

- support for research data, including large and complex data types

- gold Open Access which fosters wider collaboration and increased citations

- maximum visibility for your research: over $100 \mathrm{M}$ website views per year

At BMC, research is always in progress.

Learn more biomedcentral.com/submissions 